\title{
Los impactos de la producción de agrocombustibles en la seguridad alimentaria de El Salvador
}

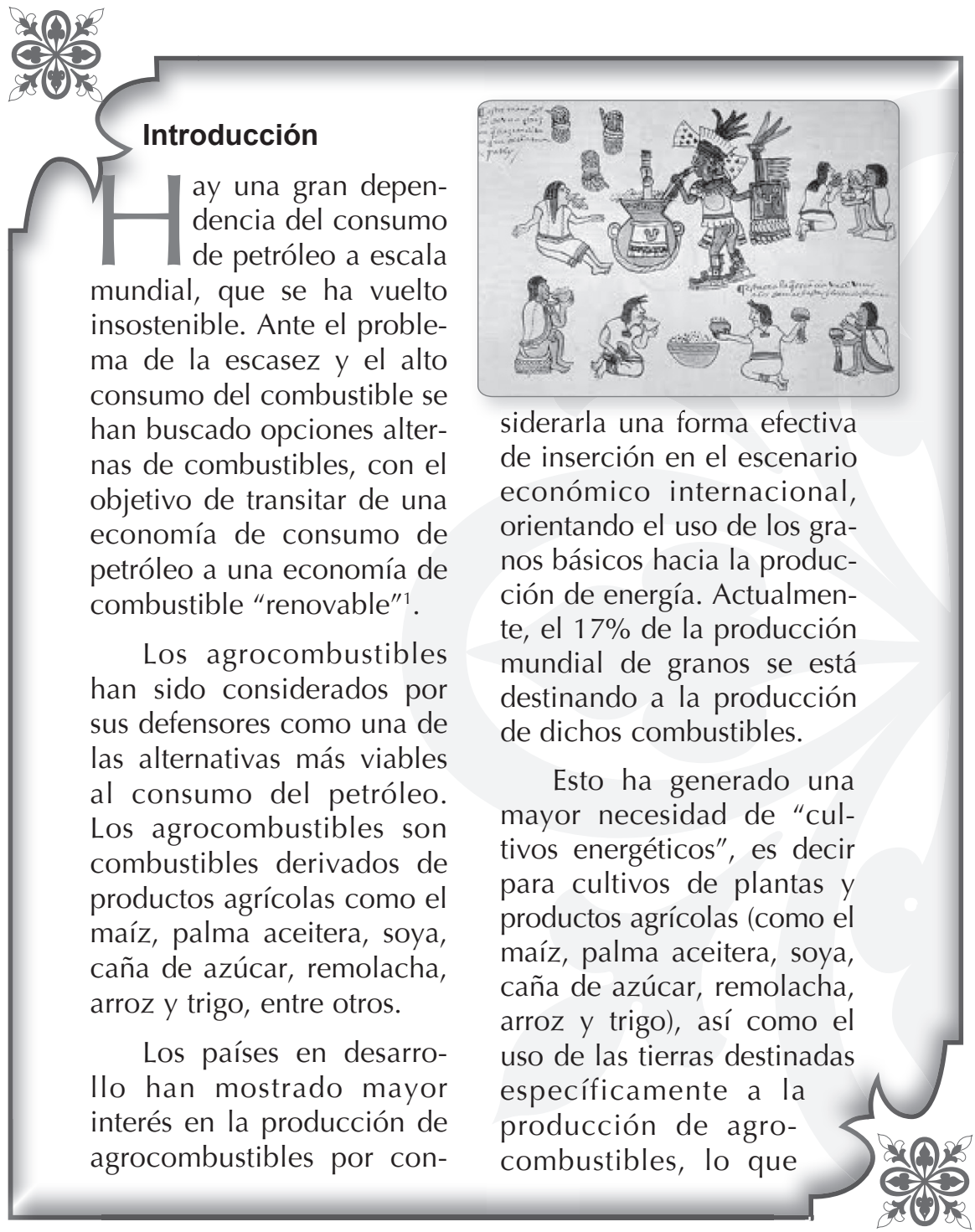


ha provocado el incremento de los precios de los insumos agrícolas y alimentos a nivel internacional, poniendo así en mayor riesgo la autosuficiencia de los países.

La importancia de estos granos dentro de la dieta alimenticia ha llevado a poner en tela de juicio la capacidad mundial para satisfacer la necesidad básica de alimentos de la población. En otras palabras, es un problema para la seguridad alimentaria ${ }^{2}$.
La situación de crisis alimenticia internacional afecta de manera directa a El Salvador, debido a que su estructura y funcionalidad agrícola no son autosuficientes. El país es importador de una parte importante de los productos alimenticios que consume.

Según el Informe Nacional de Seguimiento de la Aplicación del Plan de Acción de la Cumbre Mundial sobre la Alimentación (2002) de El Salvador,

"Para el caso del maíz amarillo, el cual casi en su totalidad es suministrado por importaciones para consumo industrial (90\%). Por su parte, el arroz es suministrado en un $70 \%$ por importaciones y solo un $25 \%$ por la producción nacional. Para el frijol, 65\% corresponde a la producción nacional y $25 \%$ a importaciones". Programa Mundial de Alimentos - PMA (2002).

El mercado de granos salvadoreño está por ende altamente vinculado con los mercados internacionales por la importación continua de granos básicos, insumos agrícolas y alimentos, lo que genera mayor presión sobre la producción agrícola nacional.

Actualmente, la superficie de la tierra salvadoreña dispone de $21 \%$ para producción de granos básicos, $20 \%$ para frutas y hortalizas. En el caso de ganadería bovina, porcina y de especies menores se utiliza un $18 \%$, mientras que para la avicultura se destina el $14 \%$. El resto de la tierra es ociosa.

En El Salvador existe interés en la producción nacional de agrocombustibles, de tal manera que resulta importante evaluar si la producción de insumos para la fabricación de agrocombustibles afectará la capacidad nacional de producción de alimentos y de acceso a estos, considerando por una parte la actual presión por una mayor demanda de granos básicos, así como también la distribución y uso de la tierra agrícola en el país.

El presente trabajo de investigación busca evaluar dichos impactos, desarrollando una investigación que se dividirá en tres partes de acuerdo a la estructura siguiente:

En la primera parte se elaborará un marco general de la seguridad alimentaría dentro del contexto internacional, permitiendo caracterizar y comprender la relación de 
los agrocombustibles y la seguridad alimentaría.

En la segunda parte se caracterizará la seguridad alimentaria de El Salvador desde tres concepciones diferentes:

1. Enfoque estructural

2. Enfoque funcionalista

3. Enfoque estructural-funcionalista

En la tercera parte se desarrollará una evaluación de la producción nacional de agrocombustibles y los impactos en la seguridad alimentaria a partir de los aspectos económicos, financieros, sociales, ambientales y técnicos del problema, así como desde el punto de vista de la oferta y la demanda de agrocombustibles, granos básicos y demás insumos agrícolas que garanticen la seguridad alimentaria de El Salvador.

Por último, con la información obtenida en los tres capítulos anteriores, se harán sugerencias para elaborar una estrategia nacional de seguridad alimentaria.

I. Marco de referencia de la relación entre seguridad alimentaria y producción de agrocombustibles

Para la presente investigación, nos apegamos a la definición de seguridad alimentaria surgida en la Cumbre Mundial sobre la Alimentación de 1996:

"Todas las personas tienen en todo momento acceso físico y económico a suficientes alimentos inocuos y nutritivos para satisfacer necesidades alimenticias y sus preferencias en cuanto a los alimentos, a fin de llevar una vida activa y sana". (FAO 1996)

Dentro de esta definición, el concepto posee tres componentes esenciales: disponibilidad, acceso, uso. Dentro de la investigación se tomará en cuenta dos nuevos componentes, el de estabilidad y el de la institucionalidad ${ }^{3}$ y marco normativo.

Según la Organización de las Naciones Unidas para la agricultura y la alimentación (FAO), dichos componentes pueden definirse de la manera siguiente:
A) Disponibilidad: Asegurar la existencia de suficientes alimentos a través de la producción interna, importaciones o cooperación solidaria de alimentos (caso de emergencia). El carácter del componente es productivo y tiene tres aspectos a considerar:

a. La agricultura familiar de subsistencia y la integración de los circuitos comerciales

b. Ventajas comparativas de cada país 
c. Ecoagricultura (uso de los recursos naturales de manera eficiente y eficaz para la producción)

B) Acceso: Condiciones de inclusión social y económica, que garantiza el derecho a la alimentación de toda la población, especialmente al sector que vive en mayor vulnerabilidad. En este caso, los instrumentos necesarios para cumplir el componente son:
a. Fomento de empleo
b. Diversificación de fuentes de ingresos
c. Fortalecimiento al acceso de activos productivos.

C) Estabilidad: Garantizar el acceso y suministro de alimentos de manera continua y estable, por medio del almacenamiento de alimentos o constitución de reservas estratégicas de estos. Por lo tanto, la construcción de políticas estarán encaminadas a cumplir la seguridad alimentaria, atendiendo dos puntos esenciales:

a. Identificación de grupos vulnerables ante situaciones de catástrofes climáticas, económicas y sociales a través de sistemas de alerta temprana, información y comunicación desde la visión de la gestión ecológica de riesgo.

b. Provisión de mecanismos e instrumentos necesarios a grupos vulnerables que les permita manejar mejor los riesgos que enfrentan.
D) Uso y aprovechamiento: Intervenciones de parte de los gobiernos por medio de políticas, programas o proyectos que generen condiciones óptimas de salud, saneamiento de los recursos, educación nutricional y manejo de los suministros alimentarios.

E) Institucionalidad: Mecanismos de políticas y programas con visión integral y multisectorial, así como también instrumentos eficaces para la planificación, monitoreo, seguimiento y evaluación de impacto de las distintas actuaciones.

El concepto de seguridad alimentaria surgió en los años 70, en el marco de la Conferencia Mundial de la Alimentación de 1974, celebrada al final de una crisis alimentaria global (1972-1974), cuyas principales causas fueron el aumento de los precios del petróleo shock petrolero) y de los fertilizantes, así como la reducción de las reservas mundiales de granos. Y en la que se buscó plantear la Seguridad alimentaria Nacional (SAN), definida en ese momento como la disponibilidad de alimentos que satisfacen las necesidades de consumo per cápita de los países, centrando el concepto de seguridad alimentaria en el componente de disponibilidad.

Para finales de los años 70, el concepto anterior de SAN resultó insuficiente, en tanto se constató que la hambruna no era consecuencia únicamente de la falta de abastecimiento, pues también obedecía a la escasez de recursos de 
algunos sectores para producirlos y comprarlos.

De tal manera que en la primera mitad de los años 80, surgió el concepto de la Seguridad alimentaria Familiar (SAF), que incorporó al enfoque en la familia y el individuo en la escala de análisis y se centró en el factor de acceso físico y económico; interrelacionando el hambre y la pobreza, así como el acceso a activos productivos y empleo, referido a la capacidad de compra que tiene el individuo o familia.

Una de las definiciones más influyentes de la SAF, fue la del Banco Mundial (BM), que en su informe "La pobreza y el Hambre" (1986) planteó la SAF como:

"El acceso de todas las personas, en todo tiempo, a cantidades de alimentos suficientes para una vida activa y saludable. Sus elementos esenciales son la disponibilidad de alimentos y la posibilidad de adquirirlos". (BM 1986)

Para medir la seguridad ali- índices de Disponibilidad y los de mentaria se crearon los siguientes Accesibilidad.

Tabla 1

Índices de disponibilidad: Indicadores de impacto de la seguridad alimentaria

\begin{tabular}{|c|c|c|c|c|}
\hline NOMBRE & INDICADOR & $\begin{array}{l}\text { INTERVALO DE } \\
\text { CONSTRUCCIÓN }\end{array}$ & $\begin{array}{l}\text { COMPONENTE } \\
\text { DE LA SAN }\end{array}$ & $\begin{array}{l}\text { UNIDAD DE } \\
\text { ANÁLISIS }\end{array}$ \\
\hline $\begin{array}{l}\text { Diversidad de } \\
\text { la Dieta }\end{array}$ & $\begin{array}{l}\text { El número de alimentos individuales } \\
\text { o grupos de alimentos consumidos } \\
\text { por la familia durante un período de } \\
\text { tiempo determinado ( } 24 \text { horas). Se } \\
\text { construye un puntaje de diversidad de } \\
\text { la dieta. }\end{array}$ & Bianual & $\begin{array}{c}\text { Disponibilidad } \\
\text { Acceso } \\
\text { Consumo }\end{array}$ & $\begin{array}{c}\text { Familias } \\
\text { participantes }\end{array}$ \\
\hline \multirow{2}{*}{$\begin{array}{l}\text { Suficiencia } \\
\text { del consumo } \\
\text { de alimentos } \\
\text { (energética y } \\
\text { Nutricional) }\end{array}$} & $\begin{array}{l}\text { Relación entre la energía (Kcal.) } \\
\text { proporcionada por el total de } \\
\text { alimentos consumidos en el hogar y } \\
\text { las necesidades energéticas del hogar. }\end{array}$ & 2006 y 2008 & $\begin{array}{c}\text { Disponibilidad } \\
\text { Acceso } \\
\text { Consumo }\end{array}$ & $\begin{array}{c}\text { Familias } \\
\text { participantes }\end{array}$ \\
\hline & $\begin{array}{l}\text { Relación entre el nutriente (proteínas, } \\
\text { vitaminas o minerales) proporcionado } \\
\text { por el total de alimentos consumidos } \\
\text { en el hogar y las necesidades } \\
\text { específicas de este nutriente. }\end{array}$ & 2006 y 2008 & Consumo & $\begin{array}{c}\text { Familias } \\
\text { participantes }\end{array}$ \\
\hline $\begin{array}{l}\text { Prevalencia de } \\
\text { enfermedades } \\
\text { diarreicas }\end{array}$ & $\begin{array}{l}\text { Proporción de niños o niñas menores } \\
\text { de } 5 \text { años de edad que tuvieron } \\
\text { episodios de diarreas durante los } \\
\text { quince días anteriores a la realización } \\
\text { de la encuesta con relación al total de } \\
\text { niños y niñas reportados al momento } \\
\text { de la encuesta. }\end{array}$ & Bianual & $\begin{array}{l}\text { Utilización } \\
\text { biológica }\end{array}$ & $\begin{array}{l}\text { Niños y niñas } \\
\text { menores } \\
\text { de } 5 \text { años } \\
\text { de familias } \\
\text { participantes }\end{array}$ \\
\hline $\begin{array}{l}\text { Reserva de } \\
\text { granos básicos }\end{array}$ & $\begin{array}{l}\text { Período asegurado (meses) por tipo } \\
\text { de producto para cubrir la demanda } \\
\text { interna familiar: Maíz - Fríjol }\end{array}$ & Bianual & $\begin{array}{c}\text { Disponibilidad } \\
\text { Acceso }\end{array}$ & $\begin{array}{c}\text { Familias } \\
\text { participantes }\end{array}$ \\
\hline
\end{tabular}




\begin{tabular}{|c|c|c|c|c|}
\hline NOMBRE & INDICADOR & \begin{tabular}{|c|} 
INTERVALO DE \\
CONSTRUCCIÓN
\end{tabular} & $\begin{array}{l}\text { COMPONENTE } \\
\text { DE LA SAN }\end{array}$ & $\begin{array}{l}\text { UNIDAD DE } \\
\text { ANÁLISIS }\end{array}$ \\
\hline $\begin{array}{l}\text { Equidad de } \\
\text { Género }\end{array}$ & Pendiente de identificar-consensuar & & $\begin{array}{l}\text { Equidad de } \\
\text { Género }\end{array}$ & $\begin{array}{c}\text { Hombres } \\
\text { y mujeres } \\
\text { de familias } \\
\text { participantes }\end{array}$ \\
\hline $\begin{array}{l}\text { Productos } \\
\text { Institucionales }\end{array}$ & $\begin{array}{l}\text { Número de productos institucionales } \\
\text { acompañados por PESA }\end{array}$ & Bianual & Institucional & $\begin{array}{c}\text { Familias, } \\
\text { comunidades, } \\
\text { alianzas, } \\
\text { Contraparte } \\
\text { Nacional u } \\
\text { otros actores }\end{array}$ \\
\hline
\end{tabular}

Fuente: Programa Especial para la Seguridad alimentaria (PESA)

\section{Índices de accesibilidad}

- Costo de una canasta básica en relación con el salario mínimo.

- Valor de los productos básicos y de una canasta en término de horas de trabajo equivalentes remuneradas al salario mínimo.

- Porcentaje destinado a los alimentos en relación con el ingreso familiar

- Identificación de línea de pobreza y porcentaje de población en esta situación.

- Índice de Precios al Consumidor (IPC) ${ }^{4}$

- Porcentaje de gastos destinados a los alimentos

Actualmente, existe la discusión sobre los posibles efectos en la seguridad alimentaria de la producción de combustibles a base granos básicos y demás materiales orgánicos, conocidos como bio y agrocombustibles. De hecho, este tema se discutió en la XXX confe- rencia regional de la $\mathrm{FAO}$ sobre "oportunidades y desafíos de la producción de biocombustibles para la seguridad alimentaria y del medio ambiente en América Latina y el Caribe", celebrada en abril de 2008.

El uso de los biocombustibles no es reciente. De hecho, en 1900 se construyó el primer motor para biocombustible hecho de aceite de maní, y se presentó en ese mismo año el aceite de maní como biocombustible en la Exposición Internacional de París. En 1912, el ingeniero alemán Rudolf Diesel sugirió el uso de los aceites vegetales como combustibles alternativos, y en 1937 se otorgó la primera patente para el uso de aceites vegetales como combustibles en Bélgica.

En los años 90, el interés hacia los biocombustibles se incrementó, sobre todo por el Ilamado cambio climático ${ }^{5}$ global, que llevó a buscar alternativas para reducir el consumo de petróleo y sus efectos negativos en el medio ambiente. 
Tabla 2

\section{Conceptualización de los bio/agrocombustibles}

\begin{tabular}{|c|c|c|}
\hline Primer nivel & Segundo nivel & Breve definición \\
\hline \multirow{4}{*}{$\begin{array}{l}\text { Combustibles de } \\
\text { madera }\end{array}$} & $\begin{array}{l}\text { Combustibles de madera } \\
\text { directos }\end{array}$ & $\begin{array}{l}\text { Madera utilizada directa o indirectamente como } \\
\text { combustible, producida para fines energéticos }\end{array}$ \\
\hline & $\begin{array}{l}\text { Combustibles de madera } \\
\text { indirectos }\end{array}$ & $\begin{array}{l}\text { Principalmente, biocombustibles sólidos } \\
\text { producidos a partir de las actividades de } \\
\text { elaboración de la madera }\end{array}$ \\
\hline & $\begin{array}{l}\text { Combustibles de madera } \\
\text { recuperados }\end{array}$ & $\begin{array}{l}\text { Madera utilizada directa o indirectamente } \\
\text { como combustible, derivada de actividades } \\
\text { socioeconómicas ajenas al sector forestal }\end{array}$ \\
\hline & $\begin{array}{l}\text { Combustibles derivados de } \\
\text { la madera }\end{array}$ & $\begin{array}{l}\text { Principalmente, biocombustibles líquidos y } \\
\text { gaseosos producidos en actividades forestales y } \\
\text { por la industria de la madera }\end{array}$ \\
\hline \multirow{4}{*}{ Agrocombustibles } & $\begin{array}{l}\text { Cultivos destinados a } \\
\text { ser utilizados como } \\
\text { combustible }\end{array}$ & $\begin{array}{l}\text { Plantas cultivadas para la producción de } \\
\text { biocombustibles, como la caña de azúcar, } \\
\text { almidón, plantas oleaginosas, entre otras. }\end{array}$ \\
\hline & Subproductos agrícolas & $\begin{array}{l}\text { Principalmente, residuos de la recolección agrícola } \\
\text { y otros subproductos de las faenas agrícolas que } \\
\text { quedan en los campos }\end{array}$ \\
\hline & $\begin{array}{l}\text { Subproductos de origen } \\
\text { animal }\end{array}$ & $\begin{array}{l}\text { Básicamente, excretas o de ganado vacuno, equino } \\
\text { y porcino, así como de aves de corral }\end{array}$ \\
\hline & $\begin{array}{l}\text { Subproductos } \\
\text { agroindustriales }\end{array}$ & $\begin{array}{l}\text { Varios tipos de materiales, producidos } \\
\text { principalmente en las industrias de elaboración de } \\
\text { los alimentos, como bagazo y cáscaras de arroz }\end{array}$ \\
\hline
\end{tabular}

Fuente: UWET - Unified Wood Energy Terminology

\section{Tabla 3}

Tipos de Agrocombustibles

\begin{tabular}{|c|c|c|c|}
\hline Agrocombustibles & Definición & Tipos & Datos \\
\hline Etanol & $\begin{array}{l}\text { Alcohol etílico } \\
\text { que se obtiene de } \\
\text { granos, siempre } \\
\text { y cuando éstos } \\
\text { sean ricos en } \\
\text { sacarosa como } \\
\text { caña de azúcar, } \\
\text { remolacha, } \\
\text { melaza y sorgo } \\
\text { dulce, o que } \\
\text { contengan } \\
\text { mucho almidón } \\
\text { como los } \\
\text { cereales, del tipo } \\
\text { de maíz, trigo, } \\
\text { cebada, etc., o } \\
\text { por último, que } \\
\text { sean tubérculos } \\
\text { como la papa o } \\
\text { la yuca. }\end{array}$ & $\begin{array}{l}\text { 1.Alcohol hidratado: } \\
\text { Se obtiene de } \\
\text { la destilación } \\
\text { convencional y } \\
\text { contiene alrededor } \\
\text { de un } 5 \% \text { de agua. } \\
\\
\text { 2. Alcohol anhidro: } \\
\text { Se obtiene de } \\
\text { procesar el alcohol } \\
\text { hidratado y contiene } \\
\text { menos de } 1 \% \text { de } \\
\text { agua }\end{array}$ & $\begin{array}{l}\text { 1. Es menos inflamable que la gasolina } \\
\text { por lo tanto es más seguro de utilizar. } \\
\text { 2. Disminuye la dependencia de } \\
\text { los países agro-productores, del } \\
\text { abastecimiento de combustibles } \\
\text { fósiles por parte de los países } \\
\text { productores de petróleo. } \\
\text { 3. Tiene un alto índice de octano: } 105 \\
\text { Durante su combustión se } \\
\text { produce un aumento del calor } \\
\text { de vaporización, lo cual genera } \\
\text { una mayor potencia respecto a } \\
\text { la gasolina. Presenta una menor } \\
\text { densidad de energía que la gasolina, } \\
\text { el conductor debe llenar el tanque } \\
\text { del automotor con más frecuencia. } \\
\text { Contiene dos terceras partes de la } \\
\text { energía contenida por el mismo } \\
\text { volumen de la gasolina. } \\
\text { Genera emisiones altamente } \\
\text { evaporativas. }\end{array}$ \\
\hline
\end{tabular}




\begin{tabular}{|c|c|c|c|}
\hline Agrocombustibles & Definición & Tipos & Datos \\
\hline Agrodiesel & $\begin{array}{l}\text { El agrodiesel es } \\
\text { generalmente } \\
\text { conocido como } \\
\text { biodiesel. Es un } \\
\text { agrocombustible } \\
\text { que se deriva } \\
\text { de aceites } \\
\text { vegetales o } \\
\text { grasas animales, } \\
\text { y puede ser } \\
\text { utilizado como } \\
\text { sustituto total o } \\
\text { parcial del diesel } \\
\text { derivado del } \\
\text { petróleo. Puede } \\
\text { ser obtenido de } \\
\text { plantas o semillas } \\
\text { oleaginosas, tipo } \\
\text { soya, girasol, } \\
\text { higuerillo, colza, } \\
\text { palma aceitera, } \\
\text { etc. Al igual } \\
\text { que el etanol, el } \\
\text { agrodiesel puede } \\
\text { funcionar puro } \\
\text { o mezclado, } \\
\text { solo que este } \\
\text { caso se mezcla } \\
\text { con diesel de } \\
\text { petróleo. }\end{array}$ & $\begin{array}{l}\text { 1.Aceites } \\
\text { eterificados: } \\
\text { Aceites de semillas } \\
\text { oleaginosas, que } \\
\text { se someten a un } \\
\text { proceso químico } \\
\text { para obtener } \\
\text { "Ester etílico" } \\
\text { después del proceso } \\
\text { de extracción y } \\
\text { refinado. } \\
\text { 2. Aceites } \\
\text { sin eterificar: } \\
\text { Aceites extraídos } \\
\text { de semillas } \\
\text { oleaginosas con } \\
\text { alto concentrado de } \\
\text { acidez. Aptos para } \\
\text { la utilización en } \\
\text { motores especiales. } \\
\text { 3. Aceites } \\
\text { Reciclados (usados): } \\
\text { Aceites procedentes } \\
\text { del uso en la cocina, } \\
\text { que se someten } \\
\text { a temperaturas } \\
\text { elevadas que } \\
\text { ocasionan su } \\
\text { degradación. Deben } \\
\text { de realizarles ciertas } \\
\text { operaciones de } \\
\text { acondicionamiento, } \\
\text { principalmente de } \\
\text { filtración. }\end{array}$ & 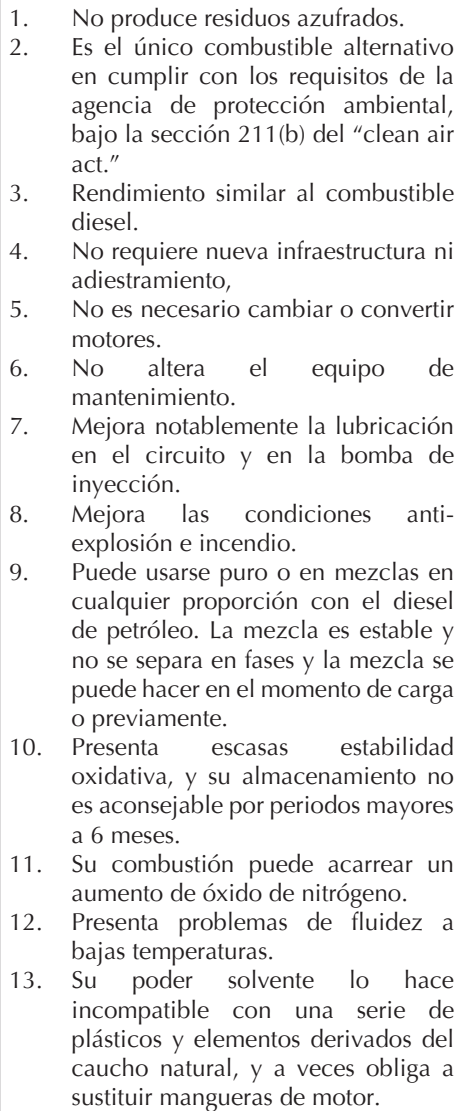 \\
\hline
\end{tabular}

Fuentes: OLADE, Subdirección de Inteligencia Competitiva (Dirección de Desarrollo Competitivo Empresarial - Ministerio de Economía de El Salvador)

El incremento en la producción y utilización de estos tipos de combustibles puede afectar la disponibilidad de granos básicos, ya que si bien es cierto, la capacidad de producción, exportación e importación de alimentos en América Latina y el Caribe es amplia, la disponibilidad de dicha producción puede estar amenazada por la re-orientación de los cultivos hacia la fabricación de combustibles.

\section{Caracterización de la seguridad alimentaria en El Salvador}

\subsection{La seguridad alimentaria en El Salvador durante 1960-1979}

En el período comprendido entre 1960-1979, la visión económica de El Salvador era de largo plazo. EI enfoque gubernamental se orientó a los obstáculos que existían para el 
acceso al mercado, tales como la concentración de tierra, el acceso a crédito, el desarrollo tecnológico, etc., enfocándose en metas de mediano plazo para superar los problemas de largo plazo. Se puede afirmar que en el período 19601979, el enfoque gubernamental de la seguridad alimentaria era estructuralista.

Tabla 4

Políticas, leyes y programas de seguridad alimentaria

\begin{tabular}{|c|c|c|}
\hline Nombre & $\begin{array}{l}\text { Año de } \\
\text { Creación }\end{array}$ & Objetivo \\
\hline \multicolumn{3}{|c|}{ Políticas Agrícolas } \\
\hline $\begin{array}{l}\text { Plan de desarrollo agropecuario } \\
\text { nacional }\end{array}$ & 1968 & $\begin{array}{l}\text { Concentrar esfuerzos en la producción interna de } \\
\text { productos alimenticios básicos para la reducción de } \\
\text { las importaciones. } \\
\text { Desarrollar la producción de materias primas y } \\
\text { promover su transformación para ayudar al proceso de } \\
\text { industrialización (Agroindustria). } \\
\text { Diversificar la producción agropecuaria. }\end{array}$ \\
\hline Ley de Avenamiento y Riego & 1970 & $\begin{array}{l}\text { Incremento de la producción de alimentos para el } \\
\text { mercado doméstico para mejorar el empleo en la zona } \\
\text { rural y a desalentar la migración a las ciudades }\end{array}$ \\
\hline $\begin{array}{l}\text { Ley para el desarrollo de una } \\
\text { Central Azucarera para la zona } \\
\text { central del país }\end{array}$ & 1974 & $\begin{array}{l}\text { Incrementar la producción de azúcar para la } \\
\text { comercialización, lo que favorecería a los pequeños } \\
\text { agricultores en sus ingresos a través de la tecnificación } \\
\text { del cultivo y del aprovechamiento de un precio } \\
\text { nacional e internacional justo. Regulado por la } \\
\text { Instituto Salvadoreño de Fomento Industrial (INSAFI). }\end{array}$ \\
\hline $\begin{array}{l}\text { Ley de creación del instituto de } \\
\text { transformación agraria (ISTA) }\end{array}$ & 1975 & $\begin{array}{l}\text { Legislar actividades de capacitación, elaboración } \\
\text { de planes, estudios técnicos de tierras. Administrar } \\
\text { temporalmente el proceso de transformación agraria. }\end{array}$ \\
\hline Política Agraria nacional & 1978 & $\begin{array}{l}\text { Incrementar la producción nacional de alimentos } \\
\text { básicos para el consumo interno. } \\
\text { Fortalecer el sector externo y contribuir al proceso de } \\
\text { sustitución de importaciones, incrementando el nivel } \\
\text { de empleo rural. }\end{array}$ \\
\hline \multicolumn{3}{|c|}{ Políticas de seguridad alimentaria } \\
\hline \multicolumn{3}{|l|}{ Ley de alimentación mínima } \\
\hline Política de Nutrición & 1978 & $\begin{array}{l}\text { Hacer accesible una alimentación adecuada a los } \\
\text { sectores de la población con bajos ingresos, aumentando } \\
\text { la producción de alimentos básicos para alcanzar y } \\
\text { mantener la autosuficiencia en dichos rubros. }\end{array}$ \\
\hline $\begin{array}{l}\text { Programa de precios y } \\
\text { comercialización de granos } \\
\text { básicos }\end{array}$ & 1978 & $\begin{array}{l}\text { Buscar la reducción de los costos de producción, } \\
\text { revisión periódico de los precios mínimos de garantía } \\
\text { para el productor y de venta para el consumidor. } \\
\text { Ampliar la estructura de almacenamiento, red de } \\
\text { distribución y comercialización en las zonas de } \\
\text { producción por parte del gobierno. }\end{array}$ \\
\hline $\begin{array}{l}\text { Programa de creación de nuevos } \\
\text { empresarios agrícolas }\end{array}$ & 1978 & $\begin{array}{l}\text { Formar un mayor número de empresarios agrícolas } \\
\text { y utilizar adecuadamente los recursos productivos } \\
\text { para alcanzar mayores niveles de producción y } \\
\text { productividad, a través de la incorporación de mayor } \\
\text { mano de obra rural. } \\
\text { Facilitar el acceso a la tierra a los trabajadores de } \\
\text { campo y elevar la participación de la mujer. }\end{array}$ \\
\hline
\end{tabular}




\begin{tabular}{|c|c|c|}
\hline Nombre & $\begin{array}{l}\text { Año de } \\
\text { Creación }\end{array}$ & Objetivo \\
\hline $\begin{array}{l}\text { Programa de modernización } \\
\text { del sistema de comercialización } \\
\text { agrícola }\end{array}$ & 1978 & $\begin{array}{l}\text { Regular el abastecimiento de los alimentos básicos } \\
\text { que garantizan la seguridad alimentaria de las familias. } \\
\text { Orientándose a la ampliación de un programa de } \\
\text { compra estacional evitando la caída de los precios del } \\
\text { agricultor y manteniendo reservas estratégicas para los } \\
\text { períodos de escasez. }\end{array}$ \\
\hline $\begin{array}{l}\text { Programa nacional de } \\
\text { alimentación y nutrición }\end{array}$ & 1978 & $\begin{array}{l}\text { Generar conciencia a la población de una alimentación } \\
\text { adecuada, principalmente al sector afectado por la } \\
\text { subalimentación y desnutrición crónica y/o estacional. }\end{array}$ \\
\hline
\end{tabular}

Fuente: Elaboración propia, en base a documentos oficiales

Los años sesenta se caracterizaron por la promulgación de leyes y decretos que impulsaron la industrialización y promovieron la integración centroamericana, que resultó en la creación del Mercado Común Centroamericano ${ }^{6}$.

El Mercado Común Centroamericano experimentó su mayor crecimiento (13.2\%) en el período de 1962 a 1966, esto por:

- Recuperación de las exportaciones tradicionales

- Establecimiento de un marco legal que protegía y proporcionaba regalías especiales a la inversión industrial

- Desarrollo de obras de infraestructura destinadas a estimular el crecimiento industrial

No obstante, a partir de 19651966, el ritmo de crecimiento del Mercado Común Centroamericano decreció drásticamente a comparación de los años anteriores. Esto aunado con la disminución de los precios internacionales del café, generó una crisis dentro de la economía salvadoreña. Sin embargo, fue la poca profundidad del mercado el mayor obstáculo del crecimiento de esta época, inconveniente que se acentuó por la mala distribución de los ingresos dentro del mercado centroamericano.

La relevancia de las importaciones dentro de los patrones de consumo poblacionales fue en aumento, teniendo mayor propensión de crecimiento en las clases altas que en las medias o bajas, ya que eran estas las que disponían con mayor capacidad de consumo.

El encarecimiento de las materias primas básicas de gran cantidad de industrias, aunado a la falta de capitales para la realización de inversiones e investigación, y al poco conocimiento técnico y científico de la mano de obra salvadoreña, limitó grandemente el rango de acción de la producción de la industria salvadoreña. Ante esta situación, a El Salvador le resultó más barato y factible importar los productos necesarios para el país, en lugar de producirlos internamente.

Durante 1971 a 1977, el crecimiento del sector se mantuvo, aunque el modelo $\mathrm{ISI}^{7}$ inicia su declive, a pesar que su objetivo era 
el ahorrar divisas al país y reducir la vulnerabilidad del sector externo.

A partir de 1979, dadas las crisis económicas, sociales y políticas, todos los sectores experimentaron un crecimiento negativo, siendo los más afectados los sectores construcción y comercio.

En lo que respecta a la disponibilidad nacional de alimentos, para 1970, se logró una mejoría en la productividad de la siembra de granos básicos, llegando a producir 8 millones de quintales de maíz.

Sin embargo, El flujo de comercialización de los granos básicos era complejo y muy caro. La comercialización se caracterizaba por la existencia de un elevado número de intermediarios entre el productor y el consumidor, de tal manera que se generaban altos márgenes de ganancia por la comercialización (el margen de comercialización variaba entre el $50 \%$ para el arroz hasta el $71 \%$ en el caso del frijol), lo cual junto con el efecto especulación, originaba altos precios para los consumidores.

Aunado a la producción interna e importaciones de alimentos, El Salvador contaba con programas de ayuda alimentaria externa. De tal manera que en los años 70 se desarrolló un programa de alimentación materno-infantil y de refrigerios escolares, ambos con donaciones del gobierno de los Estados Unidos y ejecutados por Cáritas El Salvador.
Igualmente implementó proyectos de alimentos por trabajo. Entre estos proyectos se encontraron los siguientes: Desarrollo comunal por cooperación (Dirección de Fomento y Cooperación Comunal, FOCCO) y desarrollo de la producción de cultivos alimentarios básicos para pequeños agricultores (Banco de Fomento Agropecuario con fondos del Programa Mundial de Alimentos).

Entre 1968 a 1979 los gobiernos se enfocaron en la promoción de la agricultura de los pequeños productores.

\subsection{Caracterización de la seguri- dad alimentaria en el país durante el período 1980-2000}

En la década de los años 1980, el esfuerzo gubernamental para lograr la seguridad alimentaria fue considerado dentro de los planes de desarrollo principalmente por la guerra civil. En 1981, el Gobierno por medio del Decreto N723, creó una comisión nacional encargada de la Planificación Alimentaria Nutricional de El Salvador (CONAN) y su Secretaría (SECONAN), buscando mantener la visión multicausal y multisectorial de la seguridad alimentaria.

Dentro de los planes gubernamentales, se planteó que una de las causas fundamentales del problema alimentario de la población salvadoreña era el bajo nivel de ingreso y la estructura interna de producción, distribución y comercialización de los alimentos de la canasta básica. 
Algunos de los proyectos implementados en los años 80 fueron:

- Ministerio de Educación: PMA/ ELS/2690 "Alimentación en Escuelas Primarias"

- Ministerio de Agricultura/Ministerio de Obras Públicas: PMA/ ELS/2725 "Vivienda Rural e Infraestructura Comunal en áreas de la Reforma Agraria"

- Comisión Nacional de Reforma Administrativa/Dirección de Desarrollo Comunal/Ministerio del Interior con financiamiento de la Agencia para el DesarroIlo Internacional (AID): GOES/ AID/5195613: "Ayuda Alimentaria Comunal de Emergencia"

- Ministerio de Salud: "Salud y Nutrición"

- Dirección de Desarrollo Comunal/Fuerza Armada Salvadoreña: "Programa de Ayuda Alimentaria de Emergencia"

No obstante, para finales de la década de los 80, el enfoque gubernamental dio un giro total. La CONAN/SECONAN dejó de funcionar el 1987 y los planes para lograr la Seguridad Alimentaria pasaron a segundo plano. La aplicación de una serie de reformas económicas neoliberales al final de los años 80, que se aceleraron en los años 90, introdujeron cambios dentro del aparato productivo salvadoreño, que abandonó el modelo agroexportador para basar su nuevo esquema de crecimiento en una economía terciaria.
Esto únicamente profundizó la gravedad de los mismos, impactando al mismo tiempo a la capacidad de acceso a los alimentos básicos, principalmente en el sector rural de la población.

El nuevo enfoque, llamado funcionalista, estableció al mercado como el mejor mecanismo para la asignación de los recursos. Significa que todos tienen acceso a los recursos que se necesitan (tecnología, capital, trabajo, tierra). Si la producción agrícola nacional no responde a la situación del mercado, se solventa a través de la importación.

El gobierno cerró las instituciones que asesoraban técnicamente al sector agropecuario, al igual que dejó de lado su función de ente financiero, ya que no resultó ser competitivo con respecto a la banca y demás empresa privada.

Este nuevo sistema de libre mercado llevó a importar alimentos ya que resultaba más barato que producirlos internamente.

Es por lo anterior que se puede afirmar que entre los dos enfoques de la seguridad alimentaria manejados en El Salvador durante el período 1980-2000, el enfoque gubernamental de seguridad alimentaria que prevaleció fue el funcionalista, considerando que los cambios producidos por este enfoque afectaron profundamente la estructura productiva de El Salvador, y establecieron las bases para el enfoque económico neoliberal. 
La disponibilidad nacional de alimentos en base a la producción interna de alimentos fue fluctuante en este periodo.

Hasta 1980, bajo el modelo agroexportador, El Salvador enfocó la producción interna hacia la siembra de granos para exportación como el algodón, azúcar y café, dejando de lado los granos básicos. Durante esta década, la producción nacional de granos básicos decreció considerablemente, debido principalmente al conflicto armado.

Ya en la década de los años 90 (con el cambio de enfoque económico entre 1980 y 1990, período en el que se pasó de un modelo de desarrollo agro exportador a una política económica de apertura comercial), el crecimiento de la producción nacional de granos básicos fue truncado por la disminución de la superficie destinada a su siembra desde 1991/1992, el poco apoyo para cubrir sus necesidades, así como el poco crédito destinado al sector. De tal manera que la producción nacional de granos básicos se mantuvo relativamente estable, con un leve incremento de la productividad del $0.26 \%$ entre $1989 / 90$ y 2000/01.

En cuanto a la comercialización interna de los productos básicos durante los años 80, esta se encontró bajo la potestad del Instituto Regulador de Abastecimientos (IRA). El IRA buscaba evitar el incremento de los precios de los bienes y servicios de consumo básico, de tal manera que esto no afectara la economía familiar. Se encargaba de realizar operaciones para estabilizar los precios de los granos básicos, mediante su participación como comprador mayorista y vendedor al por menor en los mercados, especialmente en las áreas rurales.

No obstante, para 1984, este mecanismo mostraba ya problemas para llevar a cabo las tareas para las que fue creado. A partir de 1989, dentro del programa de reformas económicas implementado por el gobierno salvadoreño, se procedió a la liberalización del precio de alrededor de 250 bienes, incluyendo entre otros, a los de los granos básicos. En 1991, el Instituto Regulador de Abastecimientos (IRA) cerró.

A partir de ese momento, fue el mercado el que se encargó de regir la comercialización. Los precios de los granos básicos se incrementaron por el traslado de estos costos a los consumidores finales.

En 1995 se abrió la Bolsa de Productos Agropecuarios de El Salvador (BOLPROES), la cual buscaba establecer mecanismos de comercialización más transparentes. La apertura agrícola facilitó y estimuló el proceso de importación de granos básicos. Sin embargo, dada la falta de un enfoque gubernamental hacia la sustentabilidad del sector agrícola, y por consiguiente de su política, durante el período de 1990-2000, no se ejerció prácticamente ninguna regulación a la importación de granos, de tal 
manera que entre 1980 y 2000, se incrementó continuamente el grado de dependencia del país, poniendo en riesgo su seguridad alimentaria.

Hasta 1989, la distribución de los alimentos era responsabilidad de la Dirección de Desarrollo Comunal, bajo la supervisión del Ministerio del Interior. Sin embargo, en 1990 se creó la Dirección General de Logística Alimentaria (DGLA, dependencia del Ministerio del Interior), cuyas funciones específicas eran encargarse de la internación, almacenamiento, conservación y distribución de los alimentos provenientes de los proyectos de ayuda alimentaria.

Junto a la ayuda alimentaria dada en granos básicos se recibió igualmente la ayuda alimentaria comercializable, la cual correspondió principalmente en ayuda financiera para el fortalecimiento del presupuesto gubernamental para el desarrollo de programa de asistencia alimentaria. En 1982 se creó la Secretaría Técnica del Financiamiento Externo (SETEFE), como una dependencia del Ministerio de Planificación, con el fin de administrar los fondos generados por este tipo de ayuda alimentaria.

A partir 1994, la División de Asistencia Alimentaria (DAA), se hizo cargo de la coordinación y la administración de los fondos del proyecto de la DGLA. En los años 90, el PMA apoyó políticas del Plan Sectorial de Educación y del Plan de Desarrollo Social, que buscaban promover el desarrollo humano sostenible. No obstante, los programas de ayuda desarrollados en el período 1980-2000 no llevaron a una seguridad alimentaria al país. Las importaciones, junto con la ayuda alimentaria, lejos de ayudar al campesino productor, lo perjudicaron, ya que lo volvieron menos competitivo y redujeron sus ingresos. En este contexto, los programas de ayuda contribuyeron a desplazar la producción interna, así como a profundizar la dependencia alimentaria del país.

Ante el conflicto armado, la distribución de la población salvadoreña se vio modificada al verse principalmente afectada por el fenómeno de la migración. Este cambio generó modificaciones cruciales dentro de la estructura ocupacional.

En 1978, dado que el sector agrícola era el que dinamizaba a la economía, este era, por ende, la principal fuente de empleo. Sin embargo, para 2002, luego de las reformas de liberalización económica, el comercio, las finanzas y la industria remplazaron a la agricultura como la fuente más importante de empleo. Para el período 1990-1997, la tasa anual de incremento del empleo agropecuario fue de $-2,2 \%$.

La más perjudicada fue la población rural sin tierra, ya que su acceso a los alimentos dependía de los ingresos que les proporcionaba el empleo rural agrícola y no agrícola. 
Esta situación crítica se vio profundizada por el deterioro que sufrieron los términos del intercambio interno de los granos básicos, el cual resultó de un mayor y más rápido incremento del Índice de Precios al Consumidor que el Índice de precios al Productor. A esto se le sumó el incremento del costo de la canasta básica alimentaria.

No obstante, se debe de considerar que para efectos de este estudio no se está considerando la alta desigualdad en la distribución de los ingresos, así como el hecho de que el empleo agrícola resulta ocasionalmente estacionario.

\subsection{Caracterización de la seguri- dad alimentaria en el período de 2001-2008}

La pérdida del protagonismo del sector agropecuario, aunado al contexto internacional, han Ilevado al país a una verdadera pérdida de la seguridad alimentaria.

La liberalización de los precios de productos e insumos agrícolas ha afectado a los productores agropecuarios, además el poco apoyo técnico a la producción agropecuaria llevo a un encogimiento del crédito bancario para el sector agropecuario. De tal manera que los incrementos en la producción de granos básicos (25\% entre 2000 y 2007/08), se explican casi en su totalidad por mayores rendimientos agrícolas y no aumento en las superficies sembradas.
Estos incrementos en la producción agrícola pueden explicarse en parte por los diversos proyectos implementados por el gobierno. Entre las políticas aplicadas, se encuentra el mejoramiento tecnológico por medio de la distribución y utilización de la semilla mejorada, la inversión pública en las vías de comunicación del país, la creación de nuevos puntos de encuentro, para mejorar la conectividad entre los productores y compradores, desarrollo de nuevas leyes, ampliación del crédito al sector agrícola, la modificación de la ley de semillas para permitir el uso de transgénicos, la creación de una comisión especial para la crisis alimentaria, etc.

Sin embargo, dichos incrementos no han sido suficientes para cubrir las necesidades alimenticias de El Salvador.

La perdida de importancia de la agricultura en el país afecta de gran manera la economía nacional, ya no se cuenta con ciertas funciones del sector agropecuario muy importantes dentro del crecimiento económico, tales como:

1. Capacidad de financiamiento a otras actividades económicas, a través de la reorientación de sus ganancias

2. Facultad de autosatisfacción de la demanda interna de alimentos a través de la producción nacional agrícola

3. Capacidad de absorción de mano de obra con bajos salarios. 
4. Generación de divisas, a través de la exportación de productos agrícolas

5. Contribuir a la manutención de los precios de la Canasta Básica Alimentaria gracias a la producción interna de alimentos a bajos costos, y por lo tanto permitir el acceso a los mismos

Esto, tomando en cuenta el alto grado de pobreza en el país (según el PNUD, cerca del 40\% de la población salvadoreña vive en situación de pobreza), se vuelve más crítico si se considera el fuerte incremento los precios internos, que ha afectado principalmente a la Canasta Básica Alimentaria en el último año.

Lo anterior ha hecho necesario continuar con la ejecución de programas de ayuda alimentaria externa.

Tabla 5

Programas, proyecto y políticas de seguridad alimentaria en el período de 2001-2008

\begin{tabular}{|c|c|c|}
\hline Programa & Organización & Objetivo \\
\hline \multicolumn{3}{|c|}{ Seguridad alimentaria } \\
\hline $\begin{array}{l}\text { Política Nacional de } \\
\text { Seguridad alimentaria y } \\
\text { Nutricional, que tiene como }\end{array}$ & $\begin{array}{l}\text { MAG, MSPAS, FAO, } \\
\text { INCAP, OPS, Universidad } \\
\text { de El Salvador (2003) }\end{array}$ & $\begin{array}{l}\text { Garantizar la SAN, orientando las } \\
\text { acciones del Estado y de los diferentes } \\
\text { sectores de la sociedad salvadoreña }\end{array}$ \\
\hline $\begin{array}{l}\text { Plan Nacional de Seguridad } \\
\text { alimentaria (PNSA) }\end{array}$ & MAG & $\begin{array}{l}\text { Parte de de los objetivos de la Política } \\
\text { Agrícola }\end{array}$ \\
\hline $\begin{array}{l}\text { El Proyecto de Desarrollo } \\
\text { Rural para las Poblaciones } \\
\text { del Nor-Oriente de El } \\
\text { Salvador (PRODENOR) }\end{array}$ & $\begin{array}{l}\text { Fondo Internacional de } \\
\text { Desarrollo Agrícola } \\
\text { (FIDA) }\end{array}$ & $\begin{array}{l}\text { Fortalecer la infraestructura social de las } \\
\text { comunidades } \\
\text { rurales, generar empleos e incrementar } \\
\text { los ingresos de residentes de dichas áreas, } \\
\text { mejorar los niveles de salud y nutrición en } \\
\text { niños escolares }\end{array}$ \\
\hline Red Solidaria $^{8}$ & & $\begin{array}{l}\text { Realizar transferencias de US } \$ 15.00 \text { - } \\
20.00 \text { mensuales a la madre del hogar, } \\
\text { condicionadas a la asistencia escolar } \\
\text { y participación en programas de salud } \\
\text { materno-infantil } \\
\text { Fortalecer la oferta de servicios básicos } \\
\text { en educación, salud y nutrición, así como } \\
\text { inversiones en infraestructura, servicios de } \\
\text { agua, alumbrada y saneamiento básico a } \\
\text { todas las escuelas y unidades de salud en } \\
\text { los municipios participantes } \\
\text { Desarrollar proyectos productivos y } \\
\text { micro crédito para apoyar a los pequeños } \\
\text { agricultores a diversificar sus fuentes de } \\
\text { ingreso y aumentar la productividad }\end{array}$ \\
\hline FOSALUD & MSPAS & $\begin{array}{l}\text { Ejecutar programas integrales a través } \\
\text { de la consulta médica preventiva que } \\
\text { atiendan las necesidades básicas de salud, } \\
\text { de la población mas vulnerables. }\end{array}$ \\
\hline
\end{tabular}




\begin{tabular}{|c|c|c|}
\hline Programa & Organización & Objetivo \\
\hline $\begin{array}{l}\text { Programa de Atención en } \\
\text { Salud y Nutrición a Madres y } \\
\text { menores de } 5 \text { años }\end{array}$ & MSPAS y el PMA & \\
\hline $\begin{array}{l}\text { Programa de Escuela } \\
\text { Saludable }\end{array}$ & MINED y PMA & $\begin{array}{l}\text { Proporcionar alimentación directamente } \\
\text { a } 800,000 \text { estudiantes en } 2,000 \text { escuelas } \\
\text { en las áreas rurales del país para el } \\
\text { fortalecimiento de su desarrollo. }\end{array}$ \\
\hline \multicolumn{3}{|c|}{ Agricultura } \\
\hline $\begin{array}{l}\text { Programa de Gobierno País } \\
\text { Seguro y a la Política del } \\
\text { Sector Agrícola y Ganadero } \\
\text { denominada Acciones para } \\
\text { el Desarrollo Agropecuario } \\
\text { y Agroindustrial 2004-2009: } \\
\text { Pacto por el Empleo }\end{array}$ & $\begin{array}{l}\text { MAG junto a la } \\
\text { cooperación técnica de } \\
\text { la Organización de las } \\
\text { Naciones Unidas para } \\
\text { la Agricultura y la } \\
\text { Alimentación (FAO), } \\
\text { elaboró el Plan Nacional } \\
\text { de Seguridad alimentaria } \\
\text { (PNSA) }\end{array}$ & $\begin{array}{l}\text { Contribuir a reducir el hambre y la } \\
\text { desnutrición en las poblaciones más } \\
\text { vulnerables, por medio de la ejecución de } \\
\text { acciones sostenibles, articulación de los } \\
\text { esfuerzos del sector público y privado, así } \\
\text { como la promoción y gestión de recursos } \\
\text { técnicos y financieros. }\end{array}$ \\
\hline $\begin{array}{l}\text { Programa Fomento a la } \\
\text { Productividad del Cultivo } \\
\text { de Maíz }\end{array}$ & MAG & $\begin{array}{l}\text { Incrementar la producción de granos } \\
\text { básicos, implementado el intercambio } \\
\text { de semilla mejorada o certificada que } \\
\text { comprende la producción, distribución de } \\
\text { semilla, asistencia técnica, capacitación y } \\
\text { comercialización para lograr a corto plazo } \\
\text { un aumento en la producción de maíz en } \\
\text { el país }\end{array}$ \\
\hline
\end{tabular}

Fuente: Elaboración propia, en base de información del Banco Mundial, CEPAL, MAG, FAO y PNUD

Sin embargo, desde finales de 2007, se ha llevado a cabo un viraje hacia la seguridad alimentaria, no sólo en el ámbito nacional, sino que también a escala internacional, tal como lo comprueban los diver- sos programas globales y regionales impulsados y desarrollados por diferentes instituciones internacionales, tales como FAO, ONU, USAID, INCAP, PMA, etc.

\section{Tabla 6}

\section{Programas globales y regionales de seguridad alimentaria}

\begin{tabular}{|c|c|c|}
\hline Programa & Organización & Objetivo \\
\hline \multicolumn{3}{|c|}{ Programas globales } \\
\hline $\begin{array}{l}\text { Sistema de Información } \\
\text { Global y Alerta Temprana } \\
\text { (Global Information and } \\
\text { Early Warning System, o } \\
\text { GIEWS) }\end{array}$ & $\mathrm{FAO}$ & $\begin{array}{l}\text { Informar sobre la situación global de } \\
\text { la alimentación y proporcionar alertas } \\
\text { tempranas de crisis emergentes en la } \\
\text { alimentación. }\end{array}$ \\
\hline $\begin{array}{l}\text { Análisis y Mapeo de } \\
\text { Vulnerabilidad (Vulnerability } \\
\text { Analysis and Mapping, o } \\
\text { VAM) }\end{array}$ & \multirow{2}{*}{$\begin{array}{l}\text { PMA, en coordinación } \\
\text { con FAO, ONU, Servicio } \\
\text { Geológico (USGS), } \\
\text { Administración Nacional } \\
\text { de Oceonográfica y } \\
\text { Atmosferica (NOAA) }\end{array}$} & \multirow[t]{2}{*}{ Sistema de información } \\
\hline $\begin{array}{l}\text { Servicio Humanitario } \\
\text { de Alerta Temprana } \\
\text { (Humanitarian Early Warning } \\
\text { Service, o HEWS) }\end{array}$ & & \\
\hline
\end{tabular}




\begin{tabular}{|c|c|c|}
\hline \multicolumn{3}{|c|}{ Programas regionales } \\
\hline $\begin{array}{l}\text { Sistema mesoamericana de } \\
\text { alerta temprana de Seguridad } \\
\text { alimentaria y nutricional }\end{array}$ & $\begin{array}{l}\text { FAO en coordinación } \\
\text { con la USGS, NOAA y } \\
\text { USAID. }\end{array}$ & $\begin{array}{l}\text { Actualizar y obtener información de } \\
\text { zonas de medios de vida en la región } \\
\text { mesoamericana }\end{array}$ \\
\hline $\begin{array}{l}\text { Programa Regional de } \\
\text { Seguridad alimentaria } \\
\text { y Nutricional para } \\
\text { Centroamérica (PRESANCA) }\end{array}$ & $\begin{array}{l}\text { Sistema de Integración } \\
\text { Centroamericana, } \\
\text { financiado por la Unión } \\
\text { Europea, administrado } \\
\text { por el Programa de } \\
\text { las Naciones Unidas } \\
\text { para el Desarrollo, } \\
\text { y ejecutado por el } \\
\text { Instituto de Nutrición de } \\
\text { Centroamérica y Panamá } \\
\text { (INCAP) y la FAO. }\end{array}$ & $\begin{array}{l}\text { Elaboración de estudios sobre Seguridad } \\
\text { alimentaria regional. } \\
\text { Monitoreo y seguimiento al sistema } \\
\text { regional de información sobre Seguridad } \\
\text { alimentaria nutricional y Alerta Temprana } \\
\text { en SISCA. }\end{array}$ \\
\hline $\begin{array}{l}\text { Programa Especial para la } \\
\text { Seguridad alimentaria en } \\
\text { Centroamérica (PESA) }\end{array}$ & FAO & $\begin{array}{l}\text { Desarrollar iniciativas de agrícolas para } \\
\text { garantizar la producción, estabilidad, } \\
\text { acceso uso y consumo de alimentos, } \\
\text { basadas en alianzas estratégicas de } \\
\text { desarrollo local }\end{array}$ \\
\hline $\begin{array}{l}\text { Sistema de Alerta Temprana } \\
\text { para Centroamérica (SATCA) }\end{array}$ & $\begin{array}{l}\text { Coordina con } \\
\text { instituciones como } \\
\text { MFEWS, HEWS y el } \\
\text { SNET de El Salvador }\end{array}$ & $\begin{array}{l}\text { Monitoreo de fenómenos climatológicos y } \\
\text { geológicos. }\end{array}$ \\
\hline $\begin{array}{l}\text { Secretaría Ejecutiva } \\
\text { del Consejo Regional } \\
\text { Agropecuario } \\
\text { Centroamericano (CORECA). }\end{array}$ & $\begin{array}{l}\text { Ministros de agricultura } \\
\text { de la Centroamérica. }\end{array}$ & $\begin{array}{l}\text { Brindar información de la producción y } \\
\text { consumo de granos básicos. } \\
\text { Fortalecer el monitoreo de precios } \\
\text { de granos básicos a nivel regional e } \\
\text { internacional, y actualizar las hojas de } \\
\text { balance de abastecimiento y utilización } \\
\text { de granos }\end{array}$ \\
\hline
\end{tabular}

Fuente: Elaboración propia, en base de información del Banco Mundial, CEPAL, MAG, FAO y PNUD

El nuevo interés hacia la seguridad alimentaria quedó en evidencia en el foro centroamericano sobre "Precios, mercados, regional y seguridad alimentaria y nutricional", desarrollado en San Salvador entre el 26 y 27 de mayo de 2008, en el que se estableció lo siguiente:

Entre las oportunidades para la región centroamericana, se identificaron:

-Potencial para el incremento de la productividad y aumentar la eficiencia del uso de las tierras.
- Aumentar la producción de granos básicos, fortaleciendo la complementariedad de los países centroamericanos.

- Mejorar el ingreso y calidad de vida de los pequeños productores agrícolas.

Dentro de la estrategia regional se establecieron los siguientes componentes:

- La estrategia tendrá tanto acciones nacionales y regionales.

- Los países realizaran intercambio de información de medidas de política y estadísticas, al igual 
que compartirán el desarrollo e intercambio de investigaciones en la región.

- La región centroamericana procederá a realizar en conjunto las negociaciones y/o compras de insumos, así como a coordinar la cooperación internacional técnica y financiera.

Considerando lo anterior, el CAC estableció las siguientes metas regionales para el ciclo agrícola 2008 - 2009:

- Lograr el autoabastecimiento regional del frijol rojo, frijol negro, maíz blanco para consumo humano y sorgo.

- Reducir la dependencia de importaciones en el maíz amarillo y en el arroz.

Para lograr lo anterior, el CAC determinó las siguientes medidas para aplicarse inmediatamente en todos los países centroamericanos:

-Establecimiento de programas de apoyo para la producción agrícola de granos básicos, tales como el suministro de semillas mejoradas y agroquímicos, fortalecimiento de la asistencia técnica (tanto pública y privada), financiamiento a bajas tasas de interés, programas de arrendamiento de tierras, Seguros agrícolas, creación de un fondo de garantías, etc.

-Firma de convenios de compras conjuntas de insumos a precios mínimos de referencia (granos, fertilizantes, materias primas, etc.)
—Inversión para la provisión de silos para almacenamiento, infraestructura de secado, mejoramiento del uso de fertilizantes, implementación de reservas estratégicas, etc., y ociosas.

-Aprovechamiento de tierras

\section{Evaluación multicriterio de la producción nacional de agrocombustibles}

\subsection{Definición de análisis multicri- terio}

El análisis multicriterio implica la organización y unión de la información económica y ecológica para que los/as tomadores/as de decisión tengan una base científica.

La teoría multicriterio la integran tres posiciones de pensamiento de la economía ecológica en lo que respecta al valor. La primera parte de una visión asignativa, que busca establecer métodos de comparación del valor y los flujos de capital. La unidad monetaria es usada como medio de valor y la ecuación del valor total $(\mathrm{EVT})^{9}$ como marco de referencia. Desde la visión filosófica se plantea establecer la sustentabilidad de las existencias de capital, integrando fuentes de valor no antropocéntricas.

En tanto segunda posición, la termodinámica utiliza unidades de medición comunes entre los ecosistemas y sistemas humanos. Esto se cuantifica a través de las existencias, flujos de materia y energía. 
La tercera posición, multicriterio o cualitativa, retoma la complejidad de los dos pensamientos anteriores, integrándolos para la toma de decisiones, generando una seria de alternativas y criterios para su evaluación. Además de las subjetividades, como las preferencias de los/as implicados/as.

Los criterios pueden representar objetivos, metas, valores de referencia, niveles de aspiración o utilidad. En la caracterización de un problema, la identificación de los criterios es de gran importancia para el logro de los objetivos. Operativamente se pueden clasificar en tres grupos:

1. De beneficio: la preferencia o la utilidad es creciente con el valor o puntaje del mismo;

2. De costos: ofrecen una utilidad única decreciente: cuanto mayor el puntaje, menor es la preferencia,

3. No monótonos: la utilidad máxima es obtenida en un valor intermedio dentro del rango posible.

Los criterios se miden a través de los índices siguientes: a) Relación con los objetivos de la realidad a la que se aplica, b) Basado y fundamentado en conocimiento científico, y c) de fácil aplicación, comprensión e interpretación. En el caso de los indicadores ambientales, muestran el estado actual de los ecosistemas, así como tendencias. Pueden ser geológicos, físico- químicos, hídricos, climáticos, entre otros.

\subsection{Documentación del conflicto de producción de agrocombustibles versus seguridad alimentaria}

Ante el problema de escasez y alto consumo se han buscado opciones alternas de combustibles, con el objetivo de transitar de una economía de consumo de petróleo a una economía de combustible renovable.

Para el caso de las energías renovables los agrocombustibles han sido considerados por sus defensores aunque muy cuestionada, una de las alternativas más viables. Estos se derivan de plantas como el maíz, palma aceitera, soya, caña de azúcar, remolacha, arroz y trigo, entre otros productos agrícolas.

La producción de los agrocombustibles ha sido impulsada por empresas transnacionales ${ }^{10}$ y gobiernos como Brasil y Estados Unidos, los cuales están apoyando a otros países $^{11}$ en el proceso de elaborar marcos legales que permitan impulsar la producción tanto de los insumos para los agrocombustibles como la producción de los mismos. Por ejemplo, el gobierno de los Estados Unidos ha establecido que para el año 2017 estará mezclando un mínimo de $25 \%$ de agrocombustibles con petróleo.

Los países en desarrollo han mostrado mayor interés en la producción de agrocombustibles por considerarla una forma efectiva de 
inserción en el escenario económico internacional. El Salvador no es la excepción dentro de este mercado, ya tiene más de cinco años de explorar e implementar proyectos de producción de biodiesel a partir de materias primas importadas y cultivadas localmente mediante inversiones de empresas privadas. Asimismo, han contado con la asistencia técnica del Ministerio de Agricultura y Ganadería administrado por el Centro Nacional de Tecnología Agropecuaria (CENTA).

En términos de disponibilidad de materias primas nacional existe aproximadamente 60, 000 hectáreas cultivadas con caña de azúcar (2.8\% del territorio del país). Para el caso de las oleaginosas, como el higuerillo, se estima según datos del CENTA, contar para finales del 2008 con un área cultivada 1,400 hectáreas y para el cultivo de tempate se espera un incremento del área a 240 hectáreas, la mayoría de la tierra ubicada en la parte occidental del país.

Según el Ministerio de Agricultura y Ganadería la superficie de la tierra salvadoreña disponible para producción destina aproximadamente $21 \%$ a la producción de granos básicos, 20\% a otras producciones agrícolas como frutas y hortalizas, en ganadería bovina, porcina y de especies menores en un $18 \%$; y la avicultura con $14 \%$, quedando aproximadamente más de 300,000 hectáreas no cultivadas o en situación de ocio, las cuales podrían ser destinadas para el cultivo de agro-energéticos.

De acuerdo al Informe Nacional de Seguimiento de la Aplicación del Plan de Acción de la Cumbre Mundial sobre la Alimentación (2002), "para el caso del maíz alrededor de un $80 \%$ de la disponibilidad del grano es suministrado por la producción nacional, mientras que solo un $10 \%$ es abastecido por importaciones. Caso contrario es el de maíz amarillo, el cual casi en su totalidad es suministrado por importaciones para consumo industrial (90\%). Por su parte, el arroz es suministrado en un $70 \%$ por importaciones y solo un $25 \%$ por la producción nacional. Para el frijol, $65 \%$ corresponde a la producción nacional y $25 \%$ a importaciones".

\subsection{Aspectos generales de la caña de azúcar}

El centro de producción cañera se ubica en las regiones occidental, central, paracentral y oriental del país, tal como lo muestra el mapa: 


\section{Figura 1}

\section{Mapa de zonas sembradas con caña de azúcar (2006)}

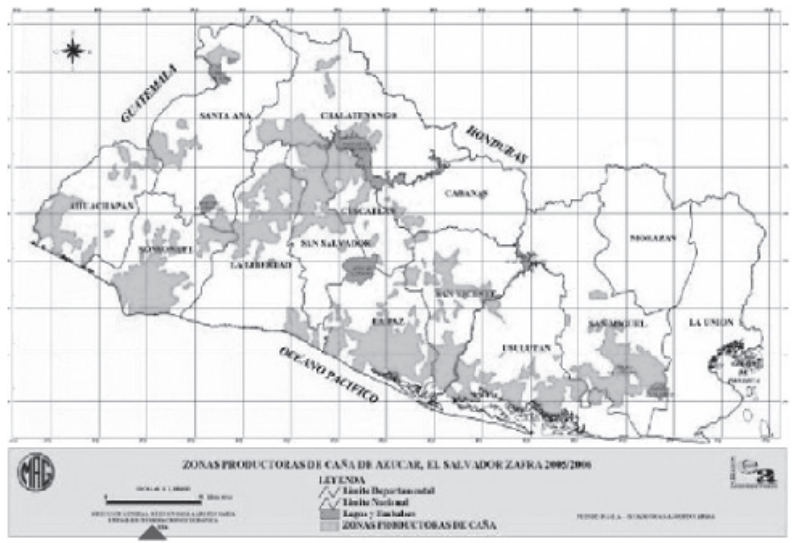

Fuente: Ministerio de Agricultura y Ganadería (MAG).

En las cuatro regiones se encuentran los siete ingenios que operan actualmente. La ubicación en el territorio es estratégica porque permite a los ingenios dar cobertura a los productores del cinturón cañero.

El uso del azúcar como materia prima en la producción del agrocombustible llamado etanol se basa en el jugo de caña extraído directamente de la molienda de la caña de azúcar (destilerías autónomas) o de las melazas (destilerías anexas).

Los tipos de destilería para la obtención de alcohol que existen en el país. La destilería autónoma y la integrada.

La destilería integrada consiste en que el ingenio abastece en cadena la materia prima y los servicios relacionados a energía eléctrica, vapor, almacenamiento de materias primas, servicios de laboratorios y servicios industriales (mantenimientos, agua, aguas servidas, etc). En el caso de la destilería autónoma se provee por sí sola los servicios asociados con la producción de alcohol, así como los servicios del ingenio.

En el mercado del azúcar, el mercado interno captura el $47 \%$ del edulcorante, siguiéndole en importancia el mundial con $42 \%$ y el preferencial en un $11 \%$. El mercado interno también es el más importante para la melaza.

De acuerdo a las estadísticas de producción, en los últimos tres años la agroindustria azucarera nacional muestra incremento en los rendimientos durante la fase industrial, resultado de innovaciones tecnológicas y mejoras en el equipo para procesar caña. Con respecto a la productividad agrícola, se observan 
mejoras, a pesar que la última zafra tuvo impactos del huracán Stan.

Según datos de la Asociación Azucarera de El Salvador (AAES) para el año 2005 el país tenía cuatro plantas de producción de etanol en los Ingenios La Cabaña, Chaparrastique, Chanmico y El Carmen. La capacidad por cada una de estas era de 469.377 galones por día.

\subsection{Identificación de actores}

La identificación de actores es necesaria para realizar la valoración socioeconómica y ecológica, ya que implica conocer los diferentes intereses y motivaciones de los agentes y actores partes del proyecto.

El Servicio Holandés de Cooperación al Desarrollo (SNV) a través de Consejo Empresarial Salvadoreño para el Desarrollo Sostenible (CEDES) realizaron en el 2007 un análisis de la cadena de valor de etanol en el país en el cual se identificaron los diferentes actores dentro del mercado nacional de azúcar que intervienen en dicha cadena. Tal como se muestra en las siguientes tablas:

\section{Tabla 7}

\section{Actores claves de la cadena de valor: Agricultores/as}

\begin{tabular}{|c|c|}
\hline \multicolumn{2}{|r|}{ Agricultores/as } \\
\hline Características & $\begin{array}{l}\text { - Pequeños productores. } \\
\text { - Tierras de } 1 \text { a } 3 \text { has. como máximo } \\
\text { - La agricultura básica es su principal fuente de ingreso (maíz, frijol, vegetales } \\
\text { huerta familiar, ganado menor, etc.) } \\
\text { - El } 45 \% \text { de los niños de las zonas rurales trabajan en la agricultura. } \\
\text { - Muchos/as pertenecientes a cooperativas de la reforma agraria }\end{array}$ \\
\hline $\begin{array}{l}\text { Relación con } \\
\text { otros actores }\end{array}$ & $\begin{array}{l}\text { - LOs agricultores actualmente involucrados, han recibo capacitación y asistencia } \\
\text { técnica de actores indirectos como el CENTA, FEyD, ODDEC, CNC, EDyTRA, } \\
\text { ANTRAPET. } \\
\text { - La relación con los productores de etanol se ha canalizado con empresas y } \\
\text { organismos internacionales interesados en la producción del etanol. } \\
\text { - El MINEC y MAG están fuertemente involucrados en darle mayor impulso ya } \\
\text { que es un mercado emergente y con grandes expectativas para el comercio } \\
\text { exterior a través de los tratados de libre comercio. }\end{array}$ \\
\hline Ámbito de acción & $\begin{array}{l}\text { - Según el Instituto Interamericano de Cooperación para la Agricultura (IICA), EI } \\
\text { Salvador cuenta con alrededor de } 20.067 \text { hectáreas disponibles y con potencial } \\
\text { para el incremento del área sembrada con caña de azúcar, sin comprometer las } \\
\text { áreas dedicadas a otros cultivos. } \\
\text { - Según datos gubernamentales, el área disponible para la siembra de caña de } \\
\text { azúcar en el país asciende a } 419.338 \text { hectáreas. }\end{array}$ \\
\hline Costos & $\begin{array}{l}\text { - Según datos del Ministerio de Agricultura y Ganadería, el costo promedio de } \\
\text { una tonelada es de aproximadamente } \$ 985.38 \text {. } \\
\text { Este dato se obtiene al promediar los costos de los cinco primeros años de } \\
\text { producción, considerando que el primer año este asciende a } \$ 1,522.48 \text {, a } \\
\$ 952.11 \text { el segundo, a } \$ 859.29 \text { el tercero, } \$ 826 \text { el cuarto y } \$ 767 \text { el quinto. }\end{array}$ \\
\hline Riesgos & $\begin{array}{l}\text { - Inadecuadas condiciones contractuales que no les genere beneficios } \\
\text { económicos. } \\
\text { - Siembra inadecuada que genera gran impacto ambiental. }\end{array}$ \\
\hline Fortalezas & $\begin{array}{l}\text { - Tienen apoyo de organizaciones que conocen sobre la producción de } \\
\text { plantaciones bioenergéticas. }\end{array}$ \\
\hline Debilidades & $\begin{array}{l}\text { - Poco conocimiento en la producción de cultivos bioenergéticos. } \\
\text { - Tienen pocas opciones de acceso al crédito }\end{array}$ \\
\hline
\end{tabular}

Fuente: Elaboración propia, a partir de datos del IICA, CNV y CEDES (2007) 


\begin{tabular}{|c|c|}
\hline \multicolumn{2}{|c|}{ Actores claves de la cadena de valor: Productores de etanol } \\
\hline \multicolumn{2}{|r|}{ Productores de etanol } \\
\hline Características & - Plantas destiladoras asociadas a ingenios azucareros. \\
\hline $\begin{array}{l}\text { Relación con } \\
\text { otros actores }\end{array}$ & $\begin{array}{l}\text { - La Fundación para la Innovación Tecnológica Agropecuaria Fiagro realizó } \\
\text { un estudio para cuatro plantas destiladoras en el país (La Cabaña, El Carmen, } \\
\text { Chanmico y Chaparrastique) } \\
\text { - Participación dentro de la creación de la Asociación de Combustibles } \\
\text { Renovables de Centroamérica, por parte de la Compañía Azucarera Salvadoreña } \\
\text { en representación de El Salvador. } \\
\text { - Presentación de una propuesta al Consejo de Ministros de la Integración } \\
\text { Económica Centroamericana para la creación de las condiciones necesarias } \\
\text { como la apertura de nuevas fracciones arancelarias y establecimiento de reglas } \\
\text { de origen, que favorezcan el invertir en la producción de etanol carburante para } \\
\text { el establecimiento de un Programa de Oxigenación de Combustibles. }\end{array}$ \\
\hline $\begin{array}{l}\text { Ámbito de } \\
\text { acción }\end{array}$ & $\begin{array}{l}\text { - La empresa Destilería Salvadoreña, S.A., cuenta con una planta productora de } \\
\text { alcohol en Apopa. Además, ha instalado otra planta en Acajutla denominada } \\
\text { Gasohol de El Salvador, S.A. de C.V. }\end{array}$ \\
\hline Costos & $\begin{array}{l}\text { - Los costos y precios del etanol aún no cuentan con un mercado lo suficientemente } \\
\text { transparente para poder establecer los verdaderos márgenes de utilidad. }\end{array}$ \\
\hline Riesgos & $\begin{array}{l}\text { - El aumento constante de los precios de los fertilizantes necesarios para la } \\
\text { siembra de caña de azúcar, afectaría la rentabilidad de las plantas de etanol, } \\
\text { considerando que las plantas de etanol están asociadas a los ingenios azucareros. } \\
\text { - La ausencia de utilidades obligaría al cierre temporal de las plantas. Aunado a las } \\
\text { dificultades financieras que experimentan los ingenios. } \\
\text { - La limitada producción de azúcar o la mala calidad de los insumos, afectaría la } \\
\text { producción del etanol. }\end{array}$ \\
\hline Fortalezas & - Apoyo del GOES. \\
\hline Debilidades & $\begin{array}{l}\text { - Poca asistencia técnica para mejorar sus procesos de producción y limitado } \\
\text { acceso al financiamiento para expandir sus actividades. }\end{array}$ \\
\hline
\end{tabular}

Fuente: Elaboración propia a partir de datos del IICA, CNV y CEDES (2007)

\section{Tabla 9}

\section{Actores involucrados en el conflicto de producción de etanol (agroetanol)}

\begin{tabular}{|c|c|c|}
\hline $\begin{array}{l}\text { A favor de la producción de } \\
\text { agrocombustibles }\end{array}$ & $\begin{array}{l}\text { En contra de la producción de } \\
\text { agrocombustibles }\end{array}$ & No han tomado posición \\
\hline $\begin{array}{ll}\text { Empresa privada: } \\
\text { 1. } \\
\text { 2. } \text { Gestilería Salvadoreña } \\
\text { 3. } \\
\text { 4. } \text { Sun Energy } \\
\text { 5. } \\
\text { 6. } & \text { ADersión Adeca Mómeda } \\
\text { 7. } & \text { Sociedad Industrial de } \\
& \text { Aceite de Ricino } \\
\text { 8. } & \text { Bioenergía } \\
\text { 9. } & \text { Antrapet } \\
\end{array}$ & Iglesia Católica & Universidades \\
\hline Ministerio de Economía & Red Sinti Techan & Ministerio de Salud \\
\hline $\begin{array}{l}\text { Ministerio de Agricultura y } \\
\text { Ganadería: CENTA }\end{array}$ & $\begin{array}{l}\text { Procuraduría para la defensa de los } \\
\text { derechos humanos (PPDH) }\end{array}$ & \\
\hline FIAGRO & Red frente a los transgénicos & \\
\hline
\end{tabular}




\begin{tabular}{|l|l|l|}
\hline $\begin{array}{c}\text { A favor de la producción de } \\
\text { agrocombustibles }\end{array}$ & \multicolumn{1}{|c|}{$\begin{array}{c}\text { En contra de la producción de } \\
\text { agrocombustibles }\end{array}$} & No han tomado posición \\
\hline AEA & $\begin{array}{l}\text { Movimiento campesino a } \\
\text { campesino }\end{array}$ & \\
\hline $\begin{array}{l}\text { Ministerio de Medio Ambiente } \\
\text { Recursos Naturales }\end{array}$ & Enlace Sur Sur & \\
\hline & CONFRAS & \\
\hline & CORDES & \\
\hline & UNES & \\
\hline & RAPAL & \\
\hline & ANTA & \\
\hline
\end{tabular}

Fuente: Elaboración propia

Una vez se ha identificado a los actores claves, es necesaria la construcción de un escenario que refleje tanto el impacto positivo como el negativo en las diferentes dimensiones socio-económica y ambientales por la producción de agrocombustibles:

Escenario A (EA): Producción de agrocombustibles como una actividad económica que mejore la economía nacional y por ende las condiciones de vida de la población.

Una vez se ha establecido el escenario, se realiza un análisis de los beneficios y costos de la producción de agrocombustibles en el país, concentrándose en la producción a través de la caña de azúcar. La metodología consiste en reflejar de manera cualitativa y cuantitativa los impactos económicos de la siembra de cultivos agroenergéticos, debido a que en el país no ha existido una entidad que elabore investigaciones en las que se evalúen los costos y los beneficios del cultivo de caña de azúcar para la producción de agroetanol.

En la siguiente tabla se muestran los beneficios y costos de manera cualitativa que tiene y tendrá la producción del agrocombustible a base de caña de azúcar. 


\begin{tabular}{|c|c|c|}
\hline \multicolumn{3}{|c|}{ Tabla 10} \\
\hline Escenarios & Beneficio & Costo \\
\hline $\begin{array}{l}\quad \quad \begin{array}{l}\text { Escenario A } \\
\quad(\text { EA) }\end{array} \\
\text { La producción de } \\
\text { agrocombustibles } \\
\text { mejora la } \\
\text { economía } \\
\text { nacional }\end{array}$ & $\begin{array}{l}\text { - Se cuenta con el Centro Salvadoreño } \\
\text { de Investigación y Exportación de la } \\
\text { Caña de Azúcar (CENSIECAÑA). Este } \\
\text { es respaldado por los Ingenios El Ángel } \\
\text { y Central Izalco. Lo que se traduce a } \\
\text { un apoyo y asesoría para incrementar } \\
\text { beneficios por parte de los ingenios } \\
\text { - Mayor valorización de la tierra en la } \\
\text { zona } \\
\text { - Aumento de inversiones productivas y } \\
\text { sociales por los flujos de las empresas } \\
\text { e ingenios paras la inversión extranjera } \\
\text { - Atractivo para los } \\
\text { varias vías. La primera por los } \\
\text { proyectos de MDL (mecanismo de } \\
\text { desarrollo limpio). Otra sería que por } \\
\text { el auge de este tipo de producción en } \\
\text { el mercado global. Así también en la } \\
\text { entrada del mercado de carbono. } \\
\text { - Sustituir importaciones de las } \\
\text { facturas petroleras e incrementar las } \\
\text { exportaciones, mejorando la balanza } \\
\text { de pagos del país. } \\
\text { - La producción de etanol es un } \\
\text { subproducto de la caña de azúcar } \\
\text { que puede generar atractivos ingresos } \\
\text { que protejan las fluctuaciones } \\
\text { - Genternacionales del precio del azúcar. } \\
\text { - Se generan divisas por medio de la } \\
\text { exportación de un subproducto no } \\
\text { tradicional a inversionistas nacionales } \\
\text { ecoeficientes Ampliación de opciones para el } \\
\text { consumidor con respecto al uso de } \\
\text { combustibles }\end{array}$ & 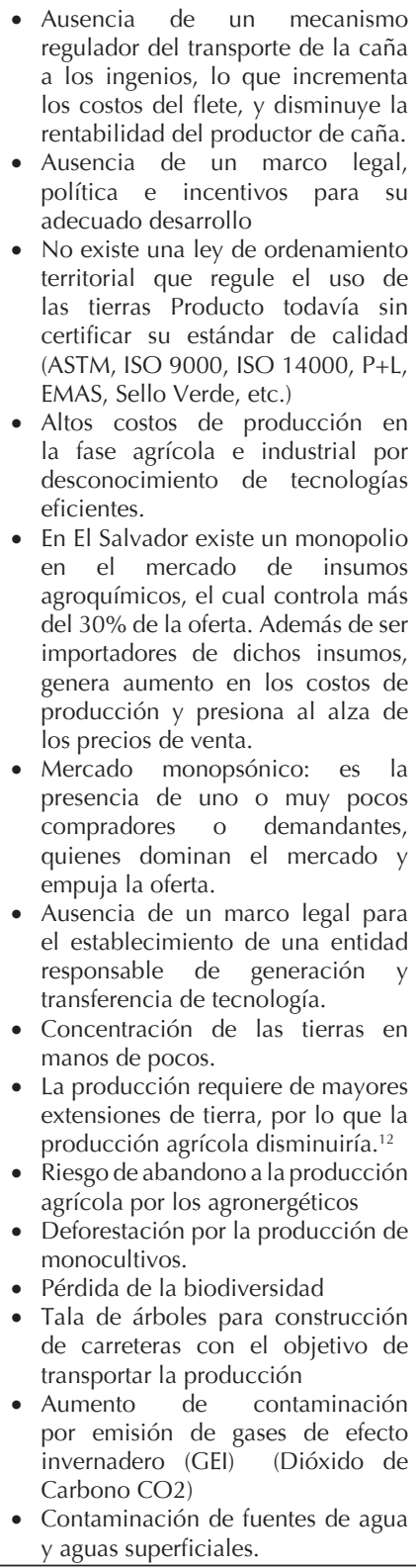 \\
\hline
\end{tabular}

Fuente: Elaboración propia. 
Para el sector cañero, la producción de agrocombustibles a partir de la caña de azúcar es un pro- yecto atractivo dentro del modelo agroindustrial, tal como se muestra en la tabla siguiente.

\section{Cuadro 1}

PROYECTO DE PLANTA DE PROCESAMIENTO DE ETANOL, SIMULACIÓN ECONÓMICA PARA EL SALVADOR (miles de dólares corrientes)

\begin{tabular}{|c|c|c|c|c|c|c|c|c|c|}
\hline \multirow{2}{*}{ Año } & \multirow{2}{*}{$\begin{array}{l}\text { Fujos de efectivo del } \\
\text { Proyecto, antes de } \\
\text { impuestos. (Ingresos } \\
\text { por procesamiento, } \\
\text { menos costos O\&M) }\end{array}$} & \multicolumn{2}{|c|}{ Deducciones fiscales } & \multirow{2}{*}{$\begin{array}{l}\text { Ingreso } \\
\text { gravable }\end{array}$} & \multirow{2}{*}{$\begin{array}{l}\text { lmpuestos } \\
\text { sobre la } \\
\text { renta } \\
(25 \%)\end{array}$} & \multirow{2}{*}{$\begin{array}{c}\text { Flujos de efectivo del } \\
\text { Proyecto, después de } \\
\text { impuestos }\end{array}$} & \multirow{2}{*}{$\begin{array}{l}\text { Pago de la } \\
\text { deuda } \\
\text { (principal }+ \\
\text { intereses) }\end{array}$} & \multirow{2}{*}{$\begin{array}{l}\text { Flujos de } \\
\text { efectivo del } \\
\text { Capital } \\
\text { Propio }\end{array}$} & \multirow{2}{*}{$\begin{array}{l}\text { Razón de } \\
\text { cobertura } \\
\text { de deuda }\end{array}$} \\
\hline & & $\begin{array}{l}\text { Depreciación } \\
\text { activos fijos }\end{array}$ & $\begin{array}{l}\text { Intereses } \\
\text { reales }\end{array}$ & & & & & & \\
\hline & (1) & (2) & (3) & $\begin{array}{c}(4) \\
=(1)-(2) \cdot(3)\end{array}$ & $\begin{array}{c}(5) \\
=(4) \times 0.25\end{array}$ & $\begin{aligned} & (6) \\
= & (1)-(5)\end{aligned}$ & (7) & $\begin{aligned} & (8) \\
= & (6)-(7)\end{aligned}$ & $\begin{aligned} & (9) \\
= & (6) /(7)\end{aligned}$ \\
\hline 0 & .10000 & & & & & .10 .000 & 5.000 & .5000 & \\
\hline 1 & 1813 & .2000 & 475 & .662 & 166 & 1978 & $\cdot 216$ & 762 & 1,63 \\
\hline 2 & 1858 & .2000 & 416 & .558 & 140 & 1998 & -1216 & 782 & 1,64 \\
\hline 3 & 1905 & .2000 & -351 & .446 & 112 & 2016 & -1216 & 800 & 1,66 \\
\hline 4 & 1952 & -2000 & .277 & -325 & 81 & 2034 & . 216 & 818 & 1,67 \\
\hline 5 & 2001 & .2000 & .195 & .194 & 49 & 2050 & .1216 & 834 & 1,69 \\
\hline 6 & 2051 & & $\cdot 103$ & 1948 & 487 & 1564 & . 216 & 348 & 1,29 \\
\hline 7 & 2102 & & & 2102 & .526 & 1577 & & 1577 & \\
\hline 8 & 2155 & & & 2155 & .539 & 1616 & & 1616 & \\
\hline 9 & 2209 & & & 2209 & .552 & 1657 & & 1657 & \\
\hline 10 & 2264 & & & 2264 & .566 & 1698 & & 1698 & \\
\hline 11 & 2321 & & & 2321 & .580 & 1741 & & 1741 & \\
\hline 12 & 2379 & & & 2379 & -595 & 1784 & & 1784 & \\
\hline $\mathrm{TIR}$ & $16,9 \%$ & & & & & $15,3 \%$ & & $17,0 \%$ & \\
\hline
\end{tabular}

Fuente: Análisis económico de precios del bioetanol para mezclas con gasolinas, CEPAL (2006).

Por su parte, el consumo estimado de etanol, suponiendo una sustitución del 10\% de la gasolina, sería el siguiente:

\subsection{Análisis de los costos de pro- ducción y precios en el mercado de agrocombustibles}

Costos de producción

El costo de materia prima comprende del 60 al 75\% del costo total de producción, siendo el costo conductor de la cadena de valor. Uno de las materias primas principales es la melaza, ya que determina la competitividad del precio en el mercado comparado al uso de combustibles fósiles. Por ejemplo, cuando el precio del barril del petróleo sube a más de $\$ 75.00$ se orienta la demanda al uso de etanol, teniendo mayor rentabilidad dicho mercado.

Una tonelada de caña de azúcar equivale entre 70 y 85 litros de jugo de caña, más 12 litros de melaza sin agotar y 6 litros de melaza agotadas.

Producir y vender internamente la materia prima, generaría mayor beneficio al país porque las divisas por importación de petróleo no saldrían del territorio nacional. Las estimaciones del MINEC reflejan que estarían girando divisas internas de $\$ 110$ a 150 millones. De tal manera, esto podría sustituir la de- 
pendencia de uso del petróleo. Para esto, se necesitarían más tierras, lo que supuestamente generaría más empleo y por lo tanto el Estado captaría mayores impuestos.

De acuerdo a la investigación realizada por Solera Chávez en el año 2006, los costos de producción se ubicarían entre un rango de \$0.15 (mínimo) y \$ 0.39 (máximo) litro de etanol anhidro ${ }^{13}$, lo que equivale a $\$ 0.55$ y $\$ 1.46$ el galón.

En los estudios sobre biocombustibles y electricidad en América Central de la Cepal (2006), se realizó la estimación de un escenario del $10 \%$ de demanda en agrocombustibles, quedando los siguientes datos:

\section{Cuadro 2}

\section{Escenario con $10 \%$ de etanol}

\begin{tabular}{|c|c|c|c|c|}
\hline $\begin{array}{c}\text { Demanda de } \\
\text { Etanol }\end{array}$ & $\begin{array}{c}\text { Disponibilidad } \\
\text { de etanol }\end{array}$ & Requerimiento & $\begin{array}{c}\text { Fracción de la } \\
\text { demanda atendida } \\
\text { por etanol }\end{array}$ & $\begin{array}{c}\text { Incremento del } \\
\text { área en caña de } \\
\text { azúcar }\end{array}$ \\
\hline Miles de $\mathbf{m} 3$ & Miles de $\mathbf{m} 3$ & Miles de $\mathbf{m} 3$ & $\%$ & $\%$ \\
\hline 52.6 & 20.1 & 32.5 & 38.2 & 9.7 \\
\hline
\end{tabular}

Fuente: Elaboración propia con base de datos en la CEPAL (2006)

\section{a. Precios}

Desde 1989 el sector azucarero experimento una relativa liberación en la reducción de aranceles para la importación del azúcar, liberación de los precios y la privatización de los ingenios de propiedad del Estado.

El mecanismo para la determinación de los precios se fundamenta en un precio ponderado con base en el precio del azúcar tanto en el mercado interno como mundial, especialmente en Estados Unidos. Esto sucede igual para el caso del precio de la melaza.

Lo anterior ha sido establecido en el artículo 30 de la ley de Producción, Industrialización y Comercialización de la Agroindustria Azucarera de El Salvador, "La fórmula para calcular el pago a los productores de caña será establecida en el "Reglamento del Sistema de Pago de Caña de Azúcar".

En el documento "Análisis de referencia: Desarrollo Competitivo. Energía Renovable en El Salvador, Etanol" (2005), el precio del barril de etanol estaría entre \$55 a 60 dólares, por lo que el precio del galón se estima entre \$1.20 a \$1.53, La estrategia agroindustrial del modelo económico actual orienta a la conversión de material orgánico en agroetanol, llevando a precios competitivos dentro del mercado internacional, lo que implica mayor inversión extranjera dentro de este rubro.

\section{b. Comercio exterior}

En los datos que presenta la partida arancelaria 22071010 del Banco Central de Reserva en los 
últimos seis años las exportaciones e importaciones de alcohol etílico han reflejado una tendencia creciente. Las exportaciones tuvieron una tasa de crecimiento media anual de $5.8 \%$ y las importaciones de $14.3 \%$.

Las exportaciones se envían principalmente a Estados Unidos, para el año 2006 se exportó el monto de $\$ 174$ millones por medio del CAFTA.

\section{c. Ámbito social}

De desarrollarse un programa de etanol en El Salvador, debido al carácter de la producción, a la ampliación de las extensas porciones de terreno necesarias para la siembra de caña de azúcar y al procesamiento necesario, la producción de etanol a partir de la caña de azúcar supone la creación de nuevas oportunidades de trabajo.

Es decir que la introducción de la producción de etanol a partir de la caña, será un factor relevante para el incremento del empleo, ya que no sólo se contemplarían los empleos generados por la producción y siembra de caña, sino que también aquellos generados en la construcción de las unidades productoras, mantenimiento, industria, comercialización y demás sectores relacionados.

Según la CEPAL (2004), la generación proyectada de empleos agrícolas en caso de desarrollar un programa de etanol en El Salvador, tanto en un escenario de demanda de mano de obra alta como baja, sería la siguiente:

\section{Cuadro 3}

\section{Generación de empleos agrícolas en caso de desarrollar un programa de etanol en El Salvador}

\begin{tabular}{|c|c|c|c|c|c|c|}
\hline \multirow{2}{*}{$\begin{array}{c}\text { Demanda de } \\
\text { etanol }(\mathbf{m i l e s} \\
\left.\text { de } \mathbf{~ m}^{3}\right)\end{array}$} & $\begin{array}{c}\text { Mano de obra } \\
\text { directa total }\end{array}$ & $\begin{array}{c}\text { Mano de obra } \\
\text { indirecta }\end{array}$ & $\begin{array}{c}\text { Total } \\
\text { General }\end{array}$ & $\begin{array}{c}\text { Mano de obra } \\
\text { directa total }\end{array}$ & $\begin{array}{c}\text { Mano de obra } \\
\text { indirecta }\end{array}$ & $\begin{array}{c}\text { Total } \\
\text { General }\end{array}$ \\
\hline 53 & 8,286 & 24,859 & 33,145 & 1,753 & 5,257 & 7,010 \\
\hline
\end{tabular}

Fuente: Elaboración propia a partir de datos del proyecto "Uso sustentable de hidrocarburos", de la CEPAL (2004)

\section{Cuadro 5}

Importancia de los empleos en caso de desarrollar un programa de etanol en El Salvador

\begin{tabular}{|l|c|c|c|c|c|}
\hline \multirow{2}{*}{$\begin{array}{c}\text { PEA } \\
\text { (miles de personas) }\end{array}$} & \multicolumn{4}{|c|}{ Demanda de empleos } \\
\cline { 2 - 6 } & \multicolumn{2}{|c|}{ (\% PEA total) } & \multicolumn{2}{c|}{ (\% PEA rural) } \\
\hline Total & Rural & Alta & Baja & $0.859 \%$ & $0.182 \%$ \\
\hline 2,409 & 965 & $0.344 \%$ & $0.073 \%$ & Baja \\
\hline
\end{tabular}

Fuente: Proyecto "Uso sustentable de hidrocarburos", de la CEPAL (2004).

No obstante se deben de considerar otras variables al momento de 
evaluar el empleo en el sector de la caña de azúcar.

Las condiciones laborales en los sembradíos de caña no son las óptimas. Los trabajadores no cuentan con espacios para descanso, ni cuentan con los mecanismos para protegerse del sol ya que los terrenos utilizados tienen poca sombra. Además los trabajadores se exponen también a otra práctica poco saludable: la quema de la caña, que provocan irritación en la piel. Generalmente, los ingenios no cuentan con la infraestructura adecuada para el descanso de su personal.

Otra anomalía que se observa en el empleo del sector cañero es la participación de niños en los sembradíos. Las agotadoras jornadas, el uso de instrumentos de trabajo peligrosos, la exposición a todo tipo de animales, insecticidas, abonos, etc., posturas incómodas, más cargas excesivas para su traslado, pone en peligro su salud y futuro. Esto es una de las peores formas de trabajo infantil.

Por lo que si bien es cierto que para el sector cañero, la producción de agrocombustibles a base de la caña resulta atractivo, en el caso del Escenario A, para la población salvadoreña desde la perspectiva social, no resulta igualmente beneficioso.

\section{Cuadro 6}

\section{El Salvador. Proyección del impacto de producción de etanol, 2002/03}

\begin{tabular}{|c|c|c|c|c|c|}
\hline Área (mz.) & $\begin{array}{c}\text { Producción } \\
\text { (TM) }\end{array}$ & $\begin{array}{c}\text { Rendimiento } \\
\text { (TM/mz.) }\end{array}$ & $\begin{array}{c}\text { Producción } \\
\text { adicional de } \\
\text { caña (TM) }\end{array}$ & $\begin{array}{c}\text { Área adicional } \\
\text { (mz.) }\end{array}$ & $\begin{array}{c}\text { Empleo } \\
\text { generado } \\
\text { (Jornales) } \\
(77 \text { jornales/mz } \\
\text { en un año) }\end{array}$ \\
\hline 88,571 & $4,418,960$ & 49.89 & 550,000 & $11,024.25$ & $848,867.25$ \\
\hline
\end{tabular}

Fuente: Elaboración propia con base en datos de FUSADES, 2003

Tomando las proyecciones del cuadro, 250 días laborales se necesitarían para la producción de etanol lo que equivale a un empleo de tiempo completo en actividades agrícolas. El requerimiento de jornales adicionales es igual a 3,395 en las plantaciones de azúcar. Lo que implica mayor contratación de mano de obra, pero no necesariamente en condiciones adecuadas.
Desde 2005, la disponibilidad de mano de obra salvadoreña para las actividades agrícolas no ha sido suficiente. Debido a las malas condiciones laborales y la baja remuneración que se ha estancado en los últimos siete años, el interés de los campesinos en estas labores ha decrecido. Muchos no consideran al trabajo agrícola como una oportunidad o actividad generadora de ingresos, obligándolos a buscar otras fuentes de ingreso. 
La creciente migración hacia la ciudad y hacia otros países - tanto por la búsqueda de mejores oportunidades laborales, como por los diversos desastres naturales que han afectado negativamente al sector agrícola ${ }^{14}$ — ha influido en el descenso de la mano de obra nacional destinada a labores agrícolas.

Las remesas familiares producto de las migraciones, ascendieron en 2006 a $\$ 3.315$ millones, incrementándose en $6.5 \%$ para 2007 , a $\$ 3,695.3$ millones. Sin embargo, desde el año 2008 hasta hoy las remesas han tenido un bajo crecimiento, según datos del Banco Central de Reservas, en diciembre de 2007, 351.1 millones y en diciembre de 2008, \$337,500 millones. Esto se refiere a un aproximado del $8 \%$ menos. Este fenómeno ha generado un acomodamiento en la población salvadoreña, sobre todo en los trabajadores de las actividades agrícolas.

Ante la necesidad de mano de obra agrícola, las empresas han recurrido a Honduras y Nicaragua para las contrataciones necesarias. Según la Subdirección General de Migración, en 2007 se autorizaron 908 permisos de trabajo para trabajadores nicaragüenses, 771 para trabajadores hondureños y 552 para trabajadores guatemaltecos.

Dado que la perspectiva de que el ritmo de las migraciones de salvadoreños a la ciudad o hacia otros países no disminuya en un tiempo cercano, se espera que el ingreso de inmigrantes a El Salvador para cumplir con las necesidades agrícolas (principalmente de la zafra), se incremente sobre todo luego del anuncio de Estados Unidos y Brasil en el que informaron que El Salvador encabezará un plan piloto para la producción de combustible alternativo a partir de la caña de azúcar.

\section{d. Ámbito ambiental}

A continuación se exponen los efectos e impactos que tendrán los recursos naturales más importantes para la población por la producción de agrocombustibles.

Tabla 11

Análisis del impacto ambiental

\begin{tabular}{|c|c|c|}
\hline Variable & Efecto & Impacto \\
\hline Agua & 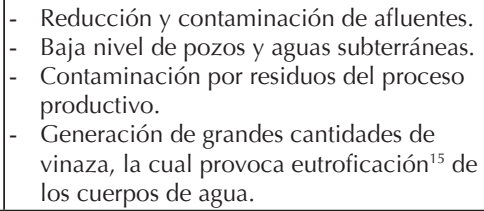 & $\begin{array}{l}\text { Aumentan los costos del recurso para los } \\
\text { diferentes usos. } \\
\begin{array}{l}\text { Aumento del costo de extracción y } \\
\text { purificación. }\end{array}\end{array}$ \\
\hline Biodiversidad & $\begin{array}{l}\text { - Pérdidas de ecosistemas agrícolas (granos } \\
\text { básicos) } \\
\text { - } \text { Aumento en el uso de pesticidas y } \\
\text { agroquímicos. } \\
\text { - Intensificación de la deforestación }\end{array}$ & $\begin{array}{l}\text { Perdida de especies vegetales y animales. } \\
\text { Menor capacidad de recarga acuífera. }\end{array}$ \\
\hline
\end{tabular}




\begin{tabular}{|c|c|c|}
\hline Variable & Efecto & Impacto \\
\hline Tierra & $\begin{array}{l}\text { - } \quad \text { Aumento de la erosión durante la labranza } \\
\text { Desgaste acelerado de fertilidad comparado } \\
\text { con cultivos permanentes. }\end{array}$ & $\begin{array}{l}\text { Desequilibrio de los nutrientes de la } \\
\text { tierra que alteran la dinámica fisiológica } \\
\text { del suelo. Esto aumenta los costos } \\
\text { de producción por el uso mayor de } \\
\text { fertilizantes. }\end{array}$ \\
\hline Aire & $\begin{array}{l}\text { - } \begin{array}{l}\text { Disminución de la calidad del aire durante } \\
\text { la quema por el aumento de partículas de } \\
\text { hollín. }\end{array} \\
\text { - Liberación de gases como el metano y } \\
\text { oxido nitroso en las diferentes fases del } \\
\text { ciclo de vida del agrocombustibles (fases } \\
\text { de la producción de materias agrícolas, } \\
\text { fabricación, transporte y almacenamiento) }\end{array}$ & $\begin{array}{l}\text { Liberación de gases de efecto invernadero } \\
\text { en las fases de producción de } \\
\text { agrocombustibles }\end{array}$ \\
\hline $\begin{array}{l}\text { Salud de las } \\
\text { personas }\end{array}$ & $\begin{array}{l}\text { - Enfermedades respiratorias y alergias, } \\
\text { erupciones en la piel } \\
\text { - Aumento de enfermedades por uso de } \\
\text { pesticidas y fertilizantes químicos. }\end{array}$ & $\begin{array}{l}\text { Aumento de los costos de salud. } \\
\text { Aumento de mortandad infantil debido a } \\
\text { enfermedades respiratorias. }\end{array}$ \\
\hline
\end{tabular}

Fuente: Elaboración propia

La producción de etanol no es una alternativa "ambientalmente amigable", tiene impactos directos en el medio ambiente y salud de la población.

Para producir un litro de etanol se necesita de 3 a 5 lts. de agua de riego y la fabricación de este desecha 13 Its de agua residuales, además de utilizar 113 lts. de gas natural. Los residuos no tienen tratamiento y son depositados en ríos aledaños y/o aguas subterráneas.

El monocultivo requiere de grandes extensiones de tierra fértil, lo cual sobreexplota los suelos, disminuyendo los nutrientes y alterando el equilibrio de los distintos ecosistemas. Los rendimientos disminuyen y se incrementa el uso de agroquímicos en la producción.

Considerando los resultados de las dimensiones del análisis multicriterio, se realiza una pequeña valoración de lo que el gobierno sal- vadoreño ha efectuado e impulsado los siguientes esfuerzos y propuestas para enfrentar las crisis alimentaria, agrícola y energética:

1. Desarrollo de una ley de arrendamiento de tierra. La propuesta está relacionada con la producción de monocultivos. Esto concentrará aún más la propiedad de la tierra, y no permitirá un desarrollo sostenible para campesinos y pequeños agricultores

2. Entrega de paquetes de semilla mejorada y fertilizantes al sector agrícola. Este proyecto lejos de estar mejorando la situación, está profundizando los problemas estructurales, al fomentar una mayor dependencia a estos insumos y sobre todo de los grandes monopolios comerciales. Una falla importante dentro de este proyecto es el escaso o nulo apoyo y asistencia técnica 
departe de las oficinas administrativas del Ministerio de Agricultura y Ganadería.

3. Uso de transgénicos. El uso de este tipo de productos y semillas, genera y profundiza la dependencia del sector agricultor de los insumos importados. Además, alteran el metabolismo de los cultivos, impidiendo la absorción de los nutrientes, lo cual provoca daños en la salud de la población como en el ambiente, principalmente en la fertilidad de la tierra.

4. Asistencia Técnica del Centro Nacional de Tecnología Agropecuaria y Forestal (CENTA). Lamentablemente, esta entidad ha perdido protagonismo, y como consecuencia, el presupuesto designado a la asistencia técnica y a la investigación agrícola no llega al nivel óptimo para lograr impulsar el sector. Actualmente, gran parte de las actividades del CENTA, se financian con donaciones, principalmente de China.

5. Eliminación de los aranceles de a los insumos agropecuarios. La liberalización del sector agrícola ha tenido un efecto contrario al deseado: en lugar de fortalecer la producción nacional, ha aumentado las importaciones, beneficiando sólo a las grandes empresas trasnacionales, las cuales tienen subsidio de sus gobiernos. Los pequeños productores no reciben subsidios y el costo de su producción es del $100 \%$, lo que obliga a bajar los precios, disminuyendo las ganancias y disminuyendo, así, la producción interna.

6. Crédito agropecuario. El sector agropecuario necesita créditos acorde a las necesidades del pequeño agricultor, que le permita un desarrollo sostenible, sin presiones financieras que ahoguen sus resultados, sino que al contrario, impulsen su desarrollo y beneficios.

7. Política Nacional de Seguridad alimentaria. La última política nacional publicada en 2003, es prácticamente inexistente, ya que ninguna entidad se responsabiliza de la aplicación, seguimiento y difusión de la misma. El gobierno debe de trabajar en una política integral de seguridad alimentaria, y comprometerse a su ejecución. Debe igualmente de aumentar la capacidad de almacenamiento de otros granos básicos, aparte del maíz y frijol, así como definir un enfoque integral que asegure la alimentación adecuada de toda la población.

\section{Conclusiones}

El fuerte y continuo incremento del precio del petróleo, junto con la gran inestabilidad de este mercado, ha Ilevado prácticamente a todos los países importadores de petróleo a buscar la forma de diversificar sus fuentes de energía, con el fin de 
reducir sus grados de dependencia del mismo y alcanzar así un mayor nivel de seguridad económica y energética.

Para lograr lo anterior, muchos países han recurrido a la incorporación de agrocombustibles en sus matrices energéticas. $Y$ han asociado a la producción de los mismos, como potenciales beneficios para las comunidades rurales y sector agrícola, la generación de ingresos adicionales por medio de la creación de nuevos empleos, generación de valor agregado a las cosechas agrícolas, mejora de las condiciones de vida de los sectores más vulnerables de la población y reactivación del sector agrícola.

Sin embargo, a pesar de que los beneficios anteriores pudieran tener efecto real, la producción de agrocombustibles tiene varios factores negativos, entre los que se puede mencionar como uno de los más importantes, la puesta en riesgo de la seguridad alimentaria de la población, ya que la producción acelerada de los agrocarburantes es uno de los factores que afectan considerablemente la seguridad alimentaria, particularmente, el acceso y/o la capacidad para adquirir alimentos.

El Salvador no es la excepción. Actualmente el país se está enfrentando una seria pérdida de seguridad alimentaria. Al mismo tiempo, tanto el sector público como el privado están buscando reducir la dependencia del petróleo y generar soluciones y combustibles alternos, enfocándose en los producidos en base a la caña de azúcar.

Para lo anterior, se utilizo el análisis multicriterio como herramienta de valoración social, ambiental y económica de la fabricación de agroetanol en el país. Fue importante haber tomado las diferentes dimensiones, ya que se obtuvo una visión integral del problema planteado y con esto se lograron concluir los posibles efectos que dicha producción pueda tener a diferente escala, así como la inclusividad y participación de los actores y sectores.

Con el instrumento se puede concluir, con respecto a los agrocombustibles, en los componentes de la seguridad alimentaria:

En cuanto a la disponibilidad, se observó que El Salvador tiene una amplia capacidad de producción, exportación e importación de alimentos, por lo que la disponibilidad de los mismos no es el principal problema para la seguridad alimentaria nacional. Además, la región presenta un mayor crecimiento relativo en la producción agropecuaria en torno a 0,7\% anual entre 1996 y 2005.

Sin embargo, la disponibilidad de un suministro adecuado de alimentos puede verse amenazada por la producción de agrocombustibles debido a la competencia por los insumos primarios, como la tierra, el agua, fertilizantes y otros recursos productivos, los que podrían 
desviarse de la producción de alimentos.

Con respecto al acceso, se observó que para el caso salvadoreño, esta es la dimensión más sensible de la seguridad alimentaria. El acceso se midió a través del índice de subnutrición, pobreza/pobreza extrema, y desigualdad. Si bien los informes recientes indican que la pobreza extrema se ha reducido en el país, todavía el $9.6 \%$ de los hogares salvadoreños vive en condiciones de extrema pobreza (dato para el 2006).

El acceso a los alimentos se verá igualmente afectado por el incremento inflacionario que actualmente experimenta El Salvador. Según los datos del BCR, llegó a 9.6\% en julio de 2008, y la perspectiva es que continúe incrementándose debido a la crisis internacional de alimentos y petróleo.

Aunado a lo anterior, se espera que la rápida expansión de la producción de agrocombustibles a nivel mundial traiga consigo efectos importantes para el sector agrícola en El Salvador. Dichos cambios afectarían la demanda, el flujo y los términos de intercambio del comercio exterior, la asignación de los insumos productivos (tierra, agua, capital, etc.), y finalmente generaría un aumento en los precios de los cultivos tradicionales y energéticos, poniendo en riesgo la capacidad monetaria de los sectores más pobres del país para el acceso a los alimentos.
En cuanto al factor de estabilidad, el riesgo de inestabilidad alimentaria está presente perennemente debido a una falta de continuidad en las políticas a largo plazo sobre seguridad alimentaria.

Además, si se considera que la estabilidad se relaciona también con la conservación de los recursos naturales, se observa que la producción en muchos casos no sólo no es sostenible, sino que destruye otros cultivos y actividades necesarios para su viabilidad. Por lo tanto, la estabilidad de la seguridad alimentaria se verá afectada por las orientaciones y el diseño de políticas y programas de agrocombustibles en la región, así como de sus manutenciones.

El mayor incentivo para la producción de agrocombustibles es el incremento en los precios del petróleo. Sin embargo, es importante notar que este aumento puede tener dos efectos que operan en sentido opuesto:

1. El aumento en el precio del petróleo aumenta los costos de producción de la agricultura, lo que pudiera resultar en una contracción de la producción;

2. El incremento en el precio del petróleo genera incentivos para la producción de agrocombustibles, lo cual estimula la demanda por cultivos energéticos.

El posible aumento de la producción de agrocombustibles depende de cuál de los dos efectos 
sea el dominante. Adicionalmente, la heterogeneidad con la que los precios del petróleo afectan los costos de producción agrícola altera los incentivos para la producción de cada uno de los cultivos energéticos, lo que a su vez puede tener impactos sobre la magnitud de los desplazamientos de otros cultivos y por ende, en los precios de estos.

En lo que concierne al factor utilización, la producción de agrocombustibles podría afectar la dimensión de utilización de la seguridad alimentaria de manera indirecta, disminuyendo la disponibilidad de agua para usos domésticos, debido a su re-direccionamiento para la elaboración de etanol y biodiesel en base a la caña de azúcar, cuyos requerimientos de agua son altos (oscilando entre 7,000 a 8.500 litros/día).

Es importante considerar que la implementación de sistemas de producción de agrocombustibles intensivos en la utilización de recursos naturales, principalmente agua, tendrá un impacto negativo sobre la producción de alimentos en ciertas zonas. Se debe de recordar que la calidad del agua $y$ del suelo, al igual que los recursos genéticos locales son la base para la preservación del modo de vida de las poblaciones rurales en el país; por lo que la contaminación de ese patrimonio, así como el uso intensivo de materias tóxicas y el consumo excesivo del agua potable, representa una amenaza directa e inminente para la seguridad alimentaria.
Si bien es cierto que los agrocombustibles representan oportunidades, no se debe olvidar que también conllevan riesgos para la seguridad alimentaria. Sus consecuencias podrán ser diversas dependiendo del espacio y el tiempo, sobre todo porque sus ramificaciones son de gran complejidad, y porque dependen de la evolución de las fuerzas y opciones del mercado así como de los avances tecnológicos. Estos elementos a su vez pueden verse influenciados por las decisiones sobre políticas adoptadas en los planos nacional e internacional. Por lo que resulta necesario preparar un marco analítico multidisciplinario a nivel nacional que considere la diversidad de situaciones y necesidades específicas de El Salvador.

En adición a las implicaciones para la seguridad alimentaria y para la estructura agrícola salvadoreña, la producción de agrocombustibles puede tener ramificaciones tanto negativas como positivas para el desarrollo agroindustrial y la creación de empleos.

En conclusión, la producción de agrocombustibles conlleva tanto oportunidades como riesgos $y$ amenazas, ya que dependen al servicio o el objetivo para quienes estén. De tal manera, se hace necesario introducir criterios de la más alta prioridad en cuanto a la sostenibilidad ambiental y social porque si esto no se logra lo demás es en vano para la sociedad, por eso debe incluirse en las políticas públicas orientadas al desarrollo de 
mercados para agrocombustibles es fundamental para minimizar los riesgos asociados a estos últimos. Debido a todas sus implicaciones y ramificaciones, el tema del impacto de la producción de agrocombustibles en la Seguridad alimentaria es de interés prioritario nacional, por lo que se requiere de una participación activa de parte del Estado para una buena producción y/o uso de agrocombustibles.

La producción de agrocombustibles, siempre y cuando se desarrolle de una manera enfocada a lo social y bajo parámetros ambientalmente sostenibles, tiene el potencial de disminuir la pobreza y generar ingresos a la población así como nuevas fuentes de empleos, sobre todo en aquellas áreas rurales que concentran los sectores más pobres y desnutridos de la población.

De tal manera, se tienen que considerar los distintos instrumentos de política necesarios para su implementación y el seguimiento de los respectivos impactos, así como

Notas

1 Se le llama energías "renovables" a las energías obtenidas de fuentes naturales aparentemente inagotables, unas por la inmensa cantidad de energía que contienen, y otras porque son capaces de regenerarse por medios naturales.

2 La satisfacción de las necesidades básicas alimenticias se analiza desde la seguridad alimentaria, definiéndose como la situación en la que la creación de mecanismos de apoyo adecuados (financieros, tecnológicos, organizacionales, asistencia técnica, etc.) que garanticen y promuevan el acceso a los alimentos a los sectores más vulnerables.

Es de vital importancia la implementación de políticas sustentables, adecuadas para reducir los riesgos de adopción de cultivos agroenergéticos sobre la seguridad alimentaria y el medioambiente. Ya que el potencial del sector agroenergético para reducir la pobreza y el hambre depende, en gran medida, de un adecuado diseño y correcta aplicación de políticas gubernamentales. Esto se logrará si se considera la producción de agroenergéticos como un instrumento para alcanzar la seguridad alimentaria y no como un fin en sí misma, teniéndose que eliminar los vicios que trae implícitos su propuesta: dependencia de agroquímicos y transgénicos, pérdida de biodiversidad, concentración de la tenencia de tierras, etc., lo cual constituye una tarea titánica.

\footnotetext{
"todas las personas tienen en todo momento acceso físico y económico a suficiente alimentos inocuos y nutritivos para satisfacer sus necesidades alimenticias y sus preferencias en cuanto a los alimentos, a fin de llevar una vida activa y sana, dentro de los componentes de disponibilidad, acceso, estabilidad y el uso o aprovechamiento biológico, todos dentro de un marco institucional favorable" (Cumbre Mundial Sobre Alimentación de 1996).
} 


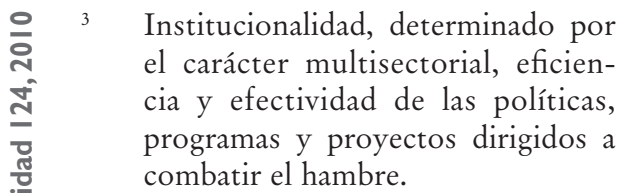

4 Concepto elaborado por el economista. Santiago Ruíz Granadino, de la Universidad de El Salvador.

5 Cambio climático: variación global del clima de la Tierra, debido a causas naturales y la acción del ser humano, producen a muy diversas escalas de tiempo y sobre todos los parámetros climáticos: temperatura, precipitaciones, nubosidad, etc.

6 Consolidación de la integración centroamericana:

- Firma del Tratado General de Integración Económica Centroamericana

- Creación de la Secretaría de Integración Centroamericana (SIECA)

- Creación del Banco centroamericano de Integración Económica (BCIE)

- Apoyo para su desarrollo de parte de la Alianza para el Progreso (Programa de ayuda económica y social de EE.UU. para América Latina efectuado entre 1961 y 1970)

- Diversificación de la estructura productiva del país ampliando en este período las industrias intermedias productoras de materias primas.

7 La estrategia del modelo ISI fue una forma distorsionada de industrialización altamente dependiente de bienes importados y con escasos vínculos intersectoriales con el resto de la economía.

8 A finales de 2007, llevó a cabo acciones en 47 municipios de pobreza extrema severa y alta, con más de 48,000 familias beneficiadas. En 2008, se extendió a 30 municipios más.
9 Ecuación del Valor Total (EVT): Se utiliza desde la perspectiva neoclásica, sin establecer límites a la aplicación que se basan en la no sustituibilidad del capital natural por el capital manufacturado.

10 Entre las cuales se encuentran Syngenta, Monsanto, Dupont, Dow, Bayer, BASF, Cargill, Archer Daniel Midland, Bunge, Royal Dutch Shell, TOTAL, British Petroleum, Volkswagen, Peugeot, Citroen, Renault y SAAB

11 Argentina, Colombia, Bolivia, Paraguay, Perú, Uruguay, Guatemala, El Salvador, Nicaragua, Honduras y Costa Rica.

12 Sistematización de impactos agrícolas del municipio de San Francisco Menéndez del Departamento de Ahuachapán. Unidad Ecológica Salvadoreña (UNES), 2008

13 Alcohol carburante, utilizado para la combinación con gasolina.

14 Como las tormentas Mitch (1998) y Stan (2004).

15 Proceso natural y/o antropogénico que consiste en el enriquecimiento de las aguas con nutrientes, a un ritmo tal que no puede ser compensado por la mineralización total, de manera que la descomposición del exceso de materia orgánica produce una disminución del oxigeno en las aguas profundas. Sus efectos pueden interferir de modo importante con los distintos usos que el hombre puede hacer de los recursos acuáticos (abastecimiento de agua potable, riego, recreación, etc.) Cfr. http:// www.cricyt.edu.ar/enciclopedia/ terminos/Eutrofizac.htm 